\title{
Axonal Regeneration and Synapse Formation in the Superior Colliculus by Retinal Ganglion Cells in the Adult Rat
}

\author{
Manuel Vidal-Sanz, Garth M. Bray, Maria P. Villegas-Pérez, Solon Thanos, ${ }^{a}$ and Albert J. Aguayo \\ Neurosciences Unit, The Montreal General Hospital and McGill University, Montréal, Québec H3G 1A4, Canada
}

In adult rats, one optic nerve was transected and replaced by a $4 \mathrm{~cm}$ segment of autologous peripheral nerve (PN) that linked one eye and the superior colliculus (SC) along a predominantly extracranial course. Retrograde and orthograde studies with the tracers HRP or rhodamine-B-isothiocyanate (RITC), as well as immunocytochemical neuronal labels, indicated the following: (1) Regenerating axons from the axotomized retinal ganglion cells extended along the entire PN grafts, covering a distance nearly twice that of the normal retinotectal projection of intact rats. (2) Some of these axons penetrated the SC and formed terminal arborizations up to $500 \mu \mathrm{m}$ from the end of the graft. (3) By electron microscopy, the arborizations of these regenerated axons in the SC were seen as small HRP-labeled axonal profiles that contacted neuronal processes in the SC; some of these contacts showed pre- and postsynaptic membrane specializations. These findings indicate that injured retinal ganglion cells in the adult rat are not only able to regrow lengthy axons, but may also form synapses in the SC.

In adult mammals, severing of retinal ganglion cell axons in the optic nerve (ON) leads to the death of many of the axotomized neurons and the failure of the surviving cells to regrow their axons (Grafstein and Ingoglia, 1982; Richardson et al., 1982; Misantone et al., 1984). However, anatomical studies using retrogradely transported tracers have demonstrated that retinal ganglion cells ( $R G C s$ ) in adult rats can regenerate axons through grafted segments of peripheral nerve (PN). When such PN grafts are inserted directly into the superior temporal retina, ganglion cells in this sector regrow long axons into the graft (So and Aguayo, 1985). Tested electrophysiologically, some of the regenerated axons from these cells respond normally to retinal stimulation by light (Keirstead et al., 1985), an indication that the axotomized-regenerated ganglion cells may retain or regain some of their functional properties. In the present studies, we

Received Dec. 17, 1986; revised Feb. 23, 1987; accepted Feb. 26, 1987.

We thank Dr. U. C. Drager and Dr. J. N. Wood for kindly providing the RT 97 monoclonal antibody. The technical assistance of $M$. David, J. Laganière, $\mathbf{S}$ Shinn, J. Trecarten, and W. Wilcox is gratefully acknowledged. H. Kim assisted with the analysis of the retinal ganglion cell sizes. M.V.-S. was supported by the Spanish Ministry of Education and Science and by the Medical Research Council of Canada. M.V.-P. was supported by the Spanish Ministry of Education and Science. S.T. was supported by the Max-Planck Gesellschaft. The Medical Research Council, the Multiple Sclerosis Society, and the Muscular Dystrophy Association of Canada provided research grants.

Correspondence should be addressed to Garth M. Bray, Neurosciences Unit, The Montreal General Hospital and McGill University, 1650 Cedar Avenue, Montréal, Québec H3G 1A4, Canada.

a Present address: Max-Planck-Institut für Entwicklungsbiologie, Tubingen, Federal Republic of Germany.

Copyright (c) 1987 Society for Neuroscience $0270-6474 / 87 / 092894-16 \$ 02.00 / 0$ transected the $O N$ within the orbit and replaced it with a $4 \mathrm{~cm}$ segment of autologous PN that joined the eye and the superior colliculus (SC) along a largely extracranial course (Vidal-Sanz et al., 1985, 1986). Because retinocollicular axons normally contact neurons in the superficial layers of the SC (Siminoff et al., 1966), it was anticipated that the appropriate placement of such PN grafts might permit some of the regrowing axons to reach target neurons in the SC, even with limited penetration of the CNS.

Thus, the main objectives of these experiments were (1) to investigate the regenerative capacities of axotomized RGCs from the entire retina; (2) to determine if axons from such retinas would grow through the grafts for the unusually long distances required for them to reach their natural targets in the SC; and (3) to investigate the morphology of the regenerating retinal axon terminals that might reach the SC. Short accounts of this work have been presented in abstract form (Vidal-Sanz et al., 1985, 1986).

\section{Materials and Methods}

Transplantation techniques

Inbred female Sprague-Dawley rats weighing 200-225 gm were anesthetized with intraperitoneal chloral hydrate $(0.42 \mathrm{mg} / \mathrm{gm}$ body weight $)$. The right common peroneal nerve was exposed, and a segment approximately $4 \mathrm{~cm}$ long was removed for autologous grafting (David and Aguayo, 1985). The posterior pole of the left eye and the origin of the $\mathrm{ON}$ were exposed through a superior temporal intraorbital approach. After longitudinally excising its dural sheath, the ON was gently separated from the dorsal aspect of the sheath and completely transected as close as possible to the eye (Vidal-Sanz et al., 1985), taking care to avoid damage to the ophthalmic artery, which is located on the inferomedial dural sheath of the ON (Janes and Bounds, 1955; Forrester and Peters, 1967).

One end of the PN graft was then placed inside the $O N$ sheath, apposed to the orbital stump of the transected $\mathrm{ON}$, and secured with $10 / 0$ sutures anchored to the adjacent sclera. The remaining portion of the PN graft was placed under the scalp along a groove drilled in the skull from the left orbit to either the left or right occipital bone (Fig. 1). The distal tip of the graft, unconnected to the brain, was tied with a silk suture and left subcutaneously over the posterior part of the skull.

The experimental animals were divided into 2 groups. Twenty-seven animals (group I) with blind-ended grafts (Fig. $1 a$ ) were used to document the extent of RGC axonal regrowth along the grafts. In another 57 animals (group II), the distal end of the graft was implanted into the contralateral (group IIa; $n=25$ ) or ipsilateral (group IIb; $n=32$ ) SC (Fig. 1b). Eight to nine weeks after the initial grafting of the PN segment to the ON, the group II animals were re-anesthetized, and the distal end of the graft was reexposed over the occipital bone, which, together with the cerebral cortex and hippocampus overlying the posterior thalamus and the rostral midbrain, was removed to expose the caudal aspect of the dorsolateral geniculate nucleus and the rostral border of the SC. The distal end of the graft was desheathed, teased into 3-4 thin strands, and gently pushed with a curved micropipette through the dorsolateral geniculate nucleus into the superficial layers of the SC. In the group IIa 
a
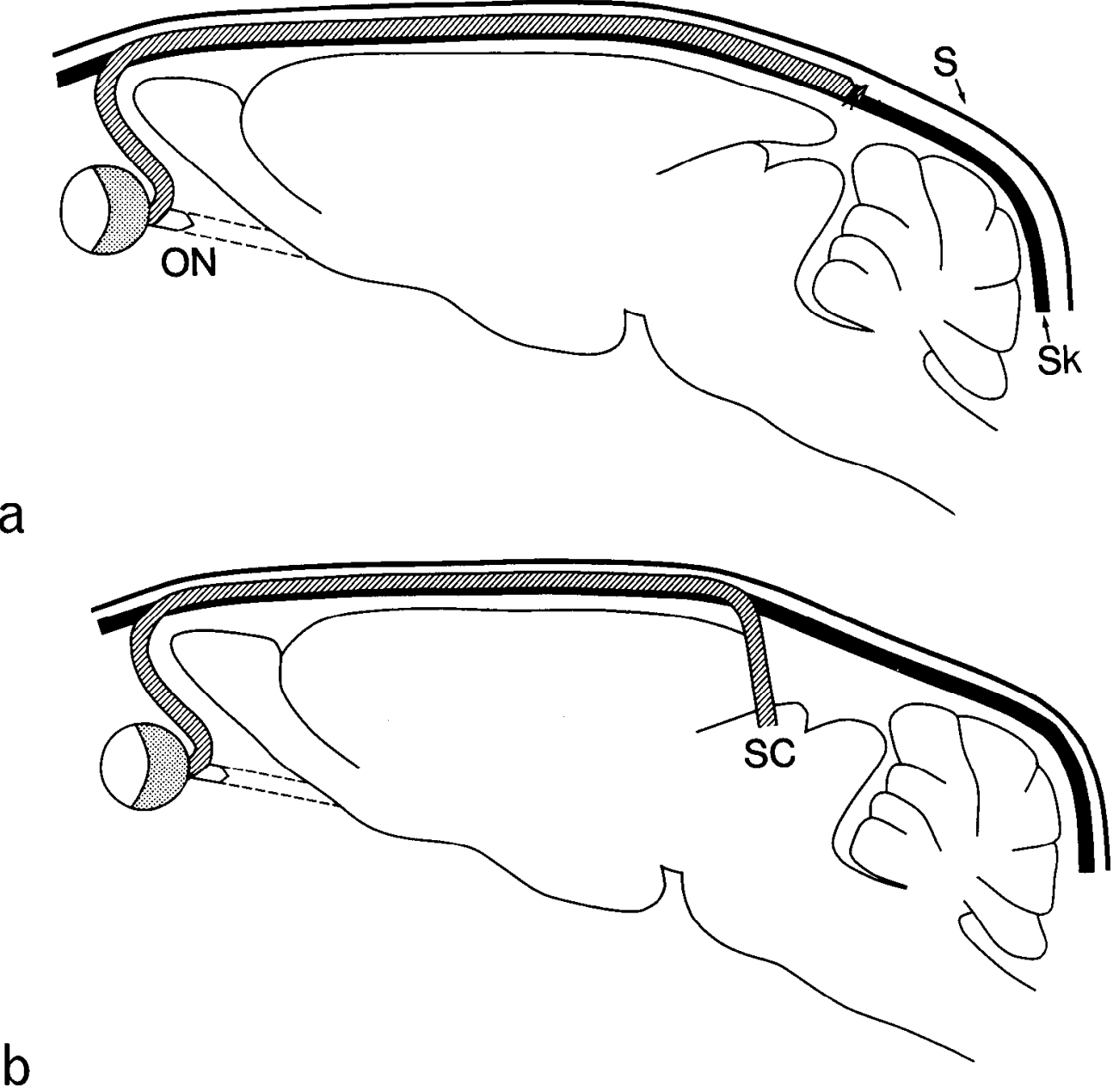

Figure 1. Diagrams of adult rat brains in sagittal section showing PN grafts (cross-hatched) used to replace the transected optic nerve $(O N)$. $a$, One end of an autologous peroneal nerve graft was attached to the orbital stump of the ON transected close to the eye. The other end of the graft was ligated and left between the scalp $(S)$ and the posterior part of the skull $(S k)$. $b$, Two to three months later, the distal end of the graft was reexposed and inserted into the superior colliculus (SC).

animals, the PN graft connected to the left $\mathrm{ON}$ was inserted into the contralateral (right) SC. In the group IIb animals, the graft was inserted into the ipsilateral (left) SC and, at the same time, the right $\mathrm{ON}$ was also transected intraorbitally.

Assessment of the arterial supply to the retina. At the beginning of the operation, the left pupil was dilated with topical application of atropine or cyclopentolate hydrochloride. Before, during, and after the grafting procedure, a drop of saline was placed on the cornea, a coverslip applicd, and the fundus oculi examined with the aid of a dissecting microscope to ascertain the state of the retinal arteries and veins. Animals whose retinas showed signs of ischemic damage were discarded.

\section{Anatomical techniques}

Identification of the retinal origins of axons regenerating along the grafts. In 20 animals of group I, the retrograde transport of HRP was used to document the retinal origins of some of the axons that had regenerated along the PN grafts. The unattached distal end of each graft was exposed in its extracranial position over the occipital bone $8-10$ weeks after the rostral end of the PN segment had been grafted to the ON. Approximately $3-3.5 \mathrm{~cm}$ from the posterior pole of the eye, a slit was made in the perineurium of the nerve graft and a small piece of Gelfoam (Upjohn, Kalamazoo, MI) soaked in 40\% HRP (Sigma Corporation, St. Louis) inserted into the nerve. Forty-eight hr later, the animals were perfused with $0.9 \% \mathrm{NaCl}$ and then $4 \%$ paraformaldehyde in $0.1 \mathrm{M}$ phosphate buffer. The PN-grafted and nongrafted (contralateral) retinas were dissected, prepared as flattened whole-mounts, immersed for $1 \mathrm{hr}$ in the fixative solution, rinsed overnight in buffer, and reacted for HRP histochemistry according to the method of Hanker et al. (1977), as modified by Perry and Linden (1982). Ten of these retinas were also incubated with RT 97 (Anderton et al., 1982), a monoclonal antibody that recognizes phosphorylated $200 \mathrm{kDa}$ neurofilaments or a closely associated protein (Nukina and Selkoe, personal communication), to visualize by fluorescence microscopy the intraretinal course of the axons of RGCs axotomized at the time of grafting. The total number and distribution of the retrogradely labeled retinal neurons that had regenerated axons along the PN grafts were determined by counting all labeled neurons in photomontages of the entire retinas printed at $45 \times(15$ animals $)$ or by preparing camera lucida drawings of all labeled neurons in the retinas ( 5 animals). The numbers obtained from these experimental animals were compared with the total population of RGCs of intact adult rats, estimated to be approximately 110,000 (Forrester and Peters, 1967 Perry, 1981; Potts et al., 1982). In 6 of these group I animals, 200 randomly selected HRP-labeled RGCs were drawn at $100 \times$, and, with the aid of an IBAS-I analyzer, soma area/frequency histograms were prepared; as a control, the soma areas were determined for 200 RGCs in a nongrafted animal $2 \mathrm{~d}$ after the application of HRP to the end of the ON transected intracranially.

In the remaining 7 animals of group I, the course of axons along the CNS-PN junction was examined in radial cryostat sections of the eye and the attached ON-PN graft segment; these sections were reacted for both RT 97 and glial fibrillary acidic protein (GFAP; Immunonuclear Corporation, Stillwater, MN) immunoreactivity, using fluorescein isothiocyanatc goat anti-mousc IgG (FITC; Bhering Diagnostics, La Jolla, $\mathrm{CA}$ ) and tetramethylrhodamine isothiocyanate swine anti-rabbit immunoglobulins (TRITC; Dako-immunoglobulins a/s., Denmark), respectively, as the secondary antibodies.

Course and termination of the regenerating axons. The course and termination of the regenerating RGC axons that reached the SC were investigated in 57 animals in which one end of the graft had been attached to the ON stump and the other end inserted into the superficial layers of the SC between 2-3 months after the initial grafting to the $\mathrm{ON}$ stump (group II). Four to eight weeks after insertion of the PN grafts into the SC of these animals, $4 \mu 1$ of $2.5 \%$ rhodamine B-isothiocyanate 


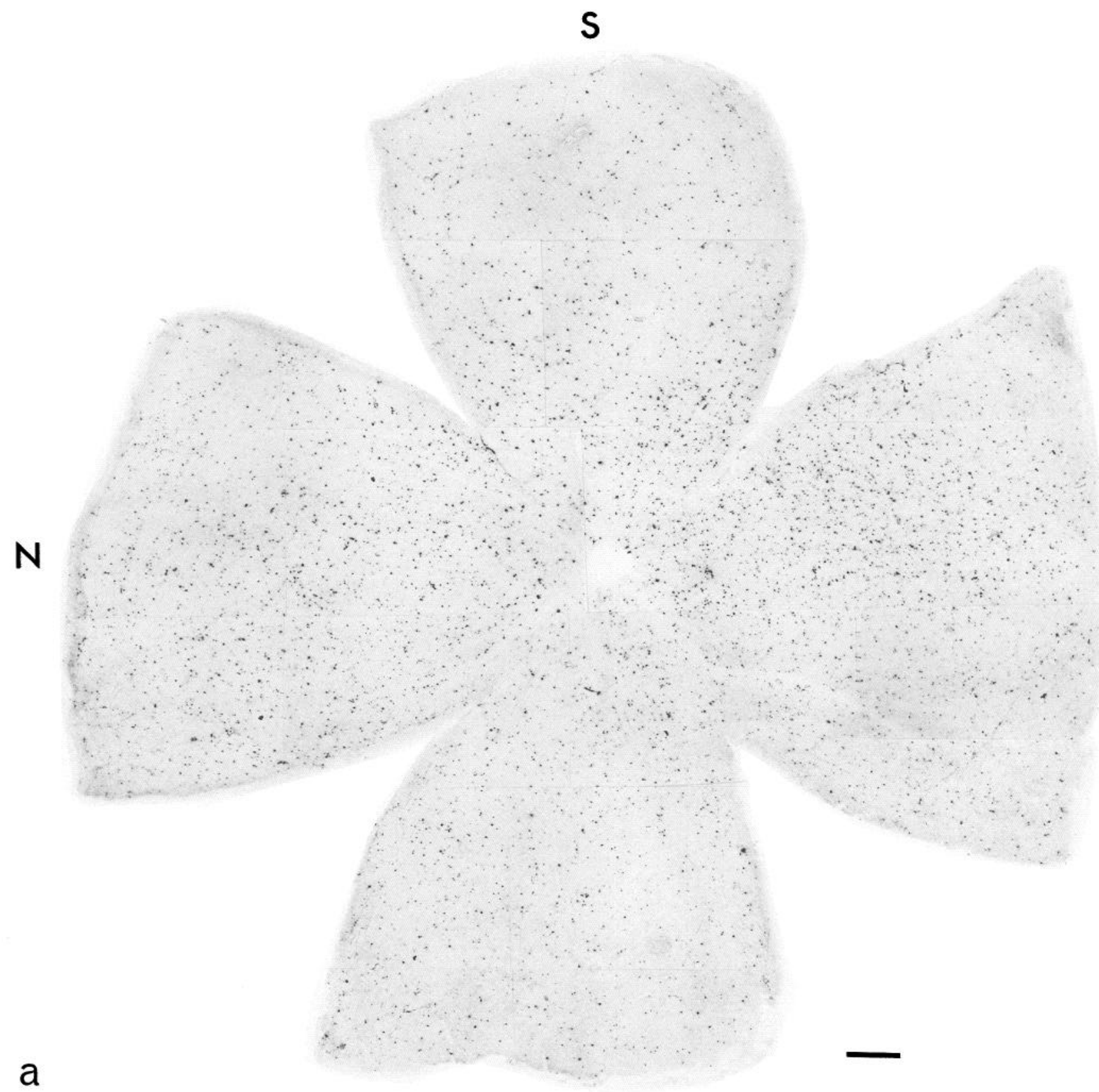

Figure 2. Photomicrographic montages of the flattened retinal whole-mount from a group I animal (N83) with a PN graft attached to the ON. The montages were prepared from 24 overlapping photographs printed at a magnification of $45 \times . S$, superior; $N$, nasal. Bars, $500 \mu \mathrm{m}$. $a$, Reacted for peroxidase histochemistry $2 \mathrm{~d}$ after application of HRP to the distal end of the graft; this retina contains 12,385 ganglion cells that are retrogradely labeled with the tracer. $b$, In the same retina, incubated with the monoclonal antibody, RT 97, the immunofluorescent axons of retinal ganglion cells converge toward the central optic disk.

(RITC-R1755; Sigma Corporation, St. Louis) dissolved in a solution of $2 \%$ dimethylsulfoxide in $0.9 \% \mathrm{NaCl}$ (Thanos et al., 1987) or $4 \mu \mathrm{l}$ of $30 \%$ HRP (Boehringer-Mannheim, Ingelheim, FRG) dissolved in 0.9\% $\mathrm{NaCl}$ was injected into the vitreous body of the PN-grafted eyes using a $10 \mu \mathrm{l}$ Hamilton syringe. These anterograde labeling methods allow the regenerating retinal axons, both in the graft and within the SC, to be distinguished from other axons originating from injured peripheral nerves in the orbit, nearby muscles, scalp, and meninges, all of which are potential sources of additional innervation of the PN grafts (for review, see Aguayo, 1985).

Five days after injection of the RITC, 4 group IIb rats were perfused with $0.9 \% \mathrm{NaCl}$ followed by $4 \%$ paraformaldehyde in $0.1 \mathrm{M}$ phosphate buffer. Longitudinal frozen sections $30 \mu \mathrm{m}$ thick were dried on glass slides and photographed under epifluorescence at $590 \mathrm{~nm}$ to identify the course and termination of RGC axons that had been anterogradely labeled with RITC injected into the eye. To visualize the overall innervation of these grafts, some of these sections were also incubated with the monoclonal antibody RT 97 (Anderton et al., 1982).

Two days after injection of HRP, 25 group IIa rats and 28 group IIb rats were perfused with $0.9 \% \mathrm{NaCl}$ and fixative solution $(2.5 \%$ glutaraldehyde and $1 \%$ paraformaldehyde in $0.1 \mathrm{~m}$ phosphate buffer). Serial coronal sections of the midbrain and thalamus were cut at $50 \mu \mathrm{m}$ with a vibrating microtome and processed for HRP histochemistry. Because the ultrastructural study of regenerated retinal axon terminals in the SC 


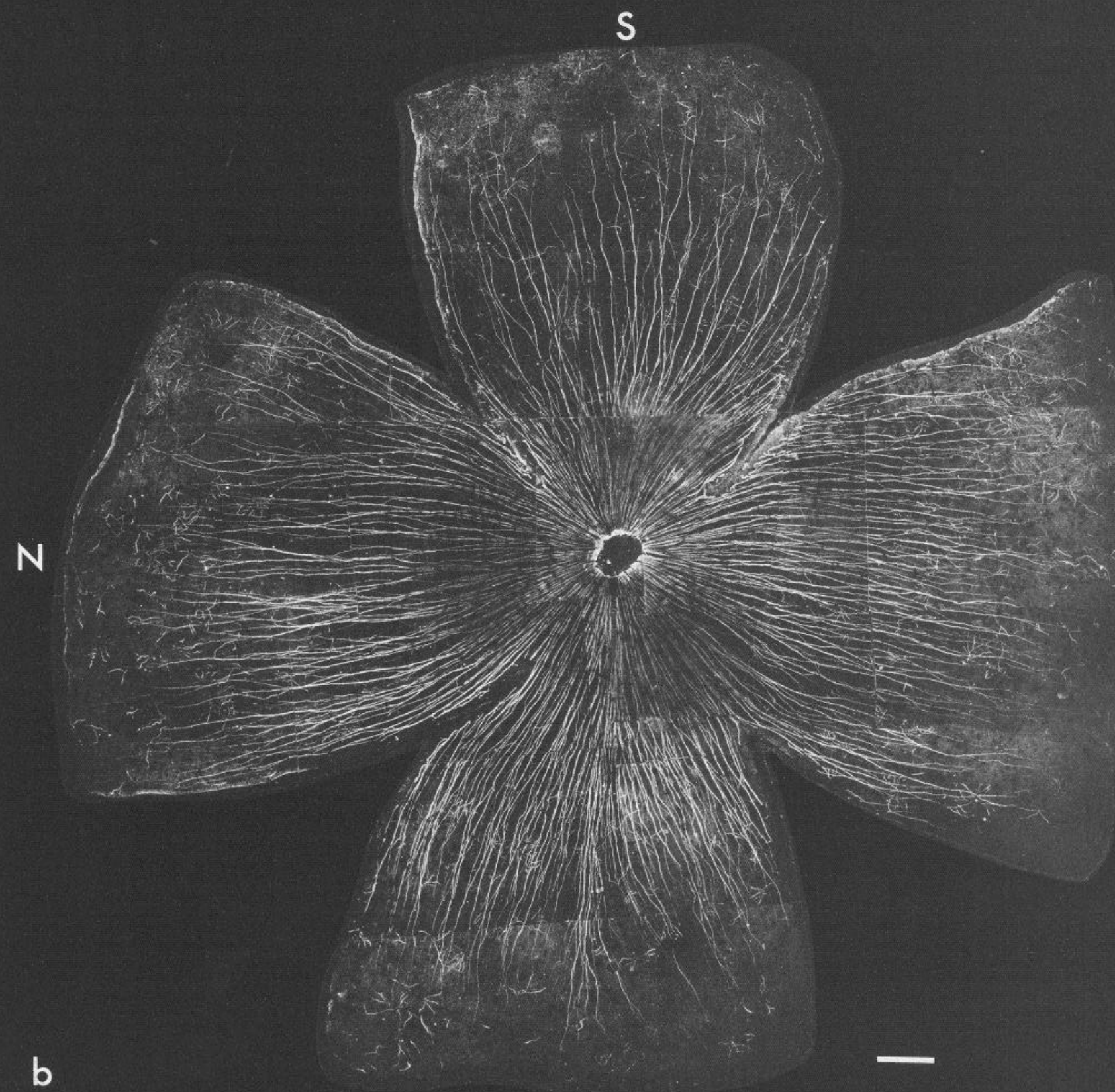

requires a method for HRP histochemistry that is both highly sensitive and capable of generating a reaction product easily detected by light as well as electron microscope, the sections were processed according to the technique of Lemann and colleagues (1985). By this method, the sections were first reacted at $\mathrm{pH} 4.0$ with tetramethylbenzidine (TMB) according to the method of Mesulam (1978); the TMB reaction product was then stabilized by reacting the sections with diaminobenzidinecobalt (DAB-Co) at $\mathrm{pH} 7.4$ using the protocol of Rye and colleagues (1984). Wet-mounted sections - were surveyed by light microscopy to identify the ends of the grafts and the HRP reaction product. Sections containing HRP reaction product were immersed for $1 \mathrm{hr}$ in $1 \%$ osmium tetroxide in $0.1 \mathrm{M}$ phosphate buffer and flat-embedded in epoxy resin.
The plastic-embedded sections were examined by light microscopy, and drawings of the ends of the grafts and the associated HRP-labeled profiles, which usually extended through several adjacent sections, were prepared by camera lucida. Ultrathin sections of selected areas of the plastic-embedded sections were examined by electron microscopy.

Precautions taken to avoid spurious labeling. Several measures were taken to assure, as far as possible, that the labeling of axon terminals in the SC was due to the orthograde transport of HRP or RITC along regenerated $\mathrm{RGC}$ axons rather than (1) the result of retrograde transport along axons from SC neurons, which are also capable of regenerating axons along PN grafts (Buenger and Aguayo, 1983); or (2) the transneuronal anterograde transport of the tracer to SC neurons. To lessen 


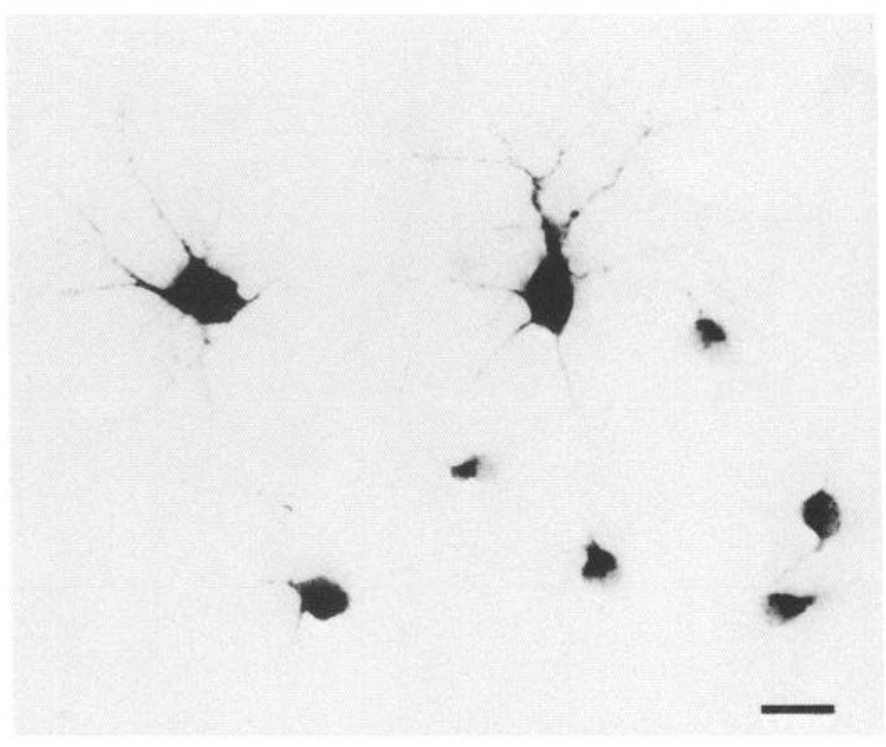

Figure 3. Light micrograph showing ganglion cells of different sizes that are retrogradely labeled with HRP in the flat-mounted retina from a group I rat (A10). Bar, $25 \mu \mathrm{m}$.

the chances of spurious retrograde transport of the tracers, labeled terminals in the SC were excluded from this study in the infrequent instances in which neuronal somata in the vicinity also contained the label. In addition, to reduce the possibility of extraneous neuronal labeling near the site of graft insertion into the SC that could have resulted from the orthograde transneuronal transport of HRP from the eye (Gerfen et al., 1982), "straight" HRP rather than HRP-conjugated wheat germ agglutinin (McLoon, 1985) was used in the present experiments.
Transneuronal transport has not been observed in the SC after intravitreal injection of RITC (Thanos et al., 1987).

\section{Results}

Gross anatomical findings

In the orbits of the experimental animals examined after fixation, each peripheral nerve graft remained attached to the posterior pole of the eye and encompassed the ocular stump of the transected ON. The remainder of the graft, located between the scalp and the skull, was loosely surrounded by connective tissue. In the animals of group II, the graft could be followed to its entry into the midbrain.

\section{Retinas}

In 20 animals of group I, flat-mounted whole retinas were examined to determine local neuronal responses and axonal extension into the grafts by a combination of RT 97 immunoreactivity and retrograde labeling with HRP (Fig. 2). The application of HRP to the extracranial ends of the grafts resulted in the labeling of many retinal neurons whose shape and size (Fig. 3), as well as position within the retinas (Figs. 2a, 4), indicated that they were ganglion cells. In 18 of the 20 animals examined, the HRP-labeled cells were evenly distributed throughout the retinas (Figs. $2 a, 4$ ). In the remaining 2 animals, there were small retinal sectors that lacked both HRP labeling and RT 97 immunoreactivity, presumably because of local ischemic damage at the time of grafting.

In control retinas obtained from the intact, nongrafted, contralateral eyes, RT 97 immunoreactivity outlined axons of RGCs. In the retinas of the PN-grafted eyes reacted with the RT 97 antibody, there were reduced numbers of RGC axons, but those
Figure 4. Diagram, drawn from a photographic montage of a flattened retinal whole-mount from a group I animal (N85), indicating the location of 9451 neurons (dots) retrogradely labeled with HRP applied to the unconnected, extracranial end of the graft. The montage was prepared from 24 overlapping photographs printed at a magnification of $45 \times . S$, superior; $N$, nasal. Bar, $500 \mu \mathrm{m}$.






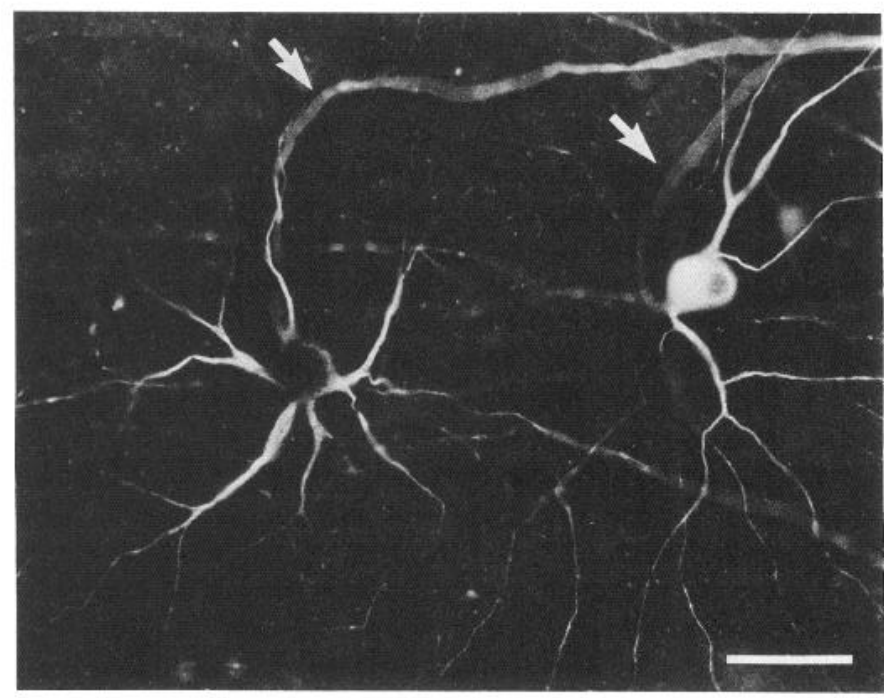

Figure 5. Ganglion cells in the retina of a group I animal. Two days after the application of HRP to the extracranial end of the graft, the retina was processed sequentially for peroxidase histochemistry and RT 97 immunoreactivity. The perikaryal cytoplasm, dendrites, and proximal axons (arrows) of both neurons show RT 97 immunofluorescence. In addition, the neuron at left has been labeled by retrograde transport of the HRP, as indicated by the dark, nonfluorescent material in the perikaryal region. Bar, $50 \mu \mathrm{m}$.

that survived retained their normal pattern of convergence towards the optic disk (Fig. 2b); there was no evidence of intraretinal collateral sprouting detectable with RT 97 immunoreactivity.

The perikarya of RGCs in the control retinas rarely showed RT 97 immunoreactivity. In the experimental retinas, not only the axons but also the somata of many retinal neurons showed RT 97 immunoreactivity (Fig. 5). This 200 kDa neurofilament-like immunoreactivity in the neuronal somata of these RGCs might be an effect of axotomy (Dräger and Hofbauer, 1984). Thus, throughout these retinas with the PN-grafted ONs, there were neuronal cell bodies showing HRP reaction product (Figs. 2a, 3), RT 97 immunoreactivity (Figs. 2b, 5), or both (Fig. 5).

\section{Number of ganglion cells regenerating long axons}

In the 20 animals of group I in which all retinal ganglion cells were axotomized by transecting the $\mathrm{ON}$ at the time of grafting, the number of retinal neurons retrogradely labeled by the application of HRP to the graft $3.0-3.5 \mathrm{~cm}$ from the eye ranged from 949 to 12,385 , with a mean of 3610 (Table 1). No labeled neurons were identified in the nongrafted (contralateral) retinas of these animals.

\section{Size of the labeled neurons}

We compared the perikaryal areas of populations of neurons retrogradely labeled in the retinas of $6 \mathrm{PN}$-grafted animals with the areas of ganglion cells in the retina of a control rat $2 \mathrm{~d}$ after intracranial ON transection and application of HRP to the ocular stump of the ON. In the normal retina, the areas of 200 randomly selected labeled RGC perikarya ranged from 43 to $411 \mu \mathrm{m}^{2}$. In the 6 retinas of the rats with PN grafts, the areas of the labeled neurons showed a similar range, although there were differences in the size-distribution histograms from animal to animal (Fig. 6). The wide spectrum of neuronal sizes that
Table 1. Number of retinal ganglion cells retrogradely labeled with HRP applied to the extracranial end of the PN graft in 20 group I animals 8-10 weeks after grafting

\begin{tabular}{lc} 
Animal no. & HRP-labeled cells/retina \\
\hline N14 & 1158 \\
N16 & 949 \\
N20 & 1526 \\
N21 & 3323 \\
N33 & 1834 \\
N34 & 3210 \\
N35 & 2985 \\
N36 & 1107 \\
N37 & 2979 \\
N45 & 3204 \\
N51 & 2886 \\
N60 & 1413 \\
N61 & 3397 \\
N86 & 4000 \\
N22 & \\
N23 & 4933 \\
N83 & 3442 \\
N84 & \\
N85 & 12385 \\
A10 & 2337 \\
Mean \pm SEM & 9451 \\
\hline
\end{tabular}

$\overline{{ }^{a}}$ Retinas in which an ischemic sector was found to be depleted of labeled cells or RT 97 immunoreactivity.

were labeled suggests that different classes of RGCs are able to regrow their severed axons into the PN grafts. In 4 of the 6 animals, there were increases in the median areas of the cell somata.

\section{$O N-P N$ graft junctions}

The junction of the ON stump and the PN graft was examined in 7 other group I animals in which radial sections of the eye and its attached ON-PN graft segment were reacted sequentially with the RT 97 monoclonal antibody to demonstrate axons and then with a GFAP antibody to delineate the ON stump (Fig. 7). Light microscopic examination of these sections suggested that many of the RT 97-immunoreactive axons extended from the ON stump into the graft.

\section{Course of the regenerating axons}

RT 97-immunoreactive axons were observed along the entire length of the PN grafts (Fig. 8). Although growth from nearby peripheral nerves injured at the time of grafting could have accounted for some of these fibers (Aguayo, 1985), the labeling of RGCs by the retrogradely transported HRP applied to the distal end of the grafts in the group I animals provided proof that retinal neurons also contributed to the innervation of the grafts. Additional evidence of RGC axonal regrowth along the grafts was obtained by injecting RITC into the vitreous body of the PN-grafted eyes in 4 of the group II animals. In such studies with this anterogradely transported substance, we observed RITC-labeled axonal profiles that extended along the 3$4 \mathrm{~cm}$ lengths of the grafts and into the SC (Fig. 9). Along the course of the graft, most of the labeled regenerating axons were arranged in parallel bundles, in contrast to the somewhat dis- 
Figure 6. Size distribution histograms of retinal ganglion cells retrogradely labeled with HRP. For the grafted retinas (solid bars), HRP was applied to the extracranial end of the graft in 6 group I animals. As a control (cross-hatched bars), the ON of a normal rat was transected intracranially (approximately 1 $\mathrm{cm}$ from the posterior eye) and HRP applied to the ocular stump. Two days later, the retinas were processed for peroxidase histochemistry. Two hundred neurons were measured in each retina.
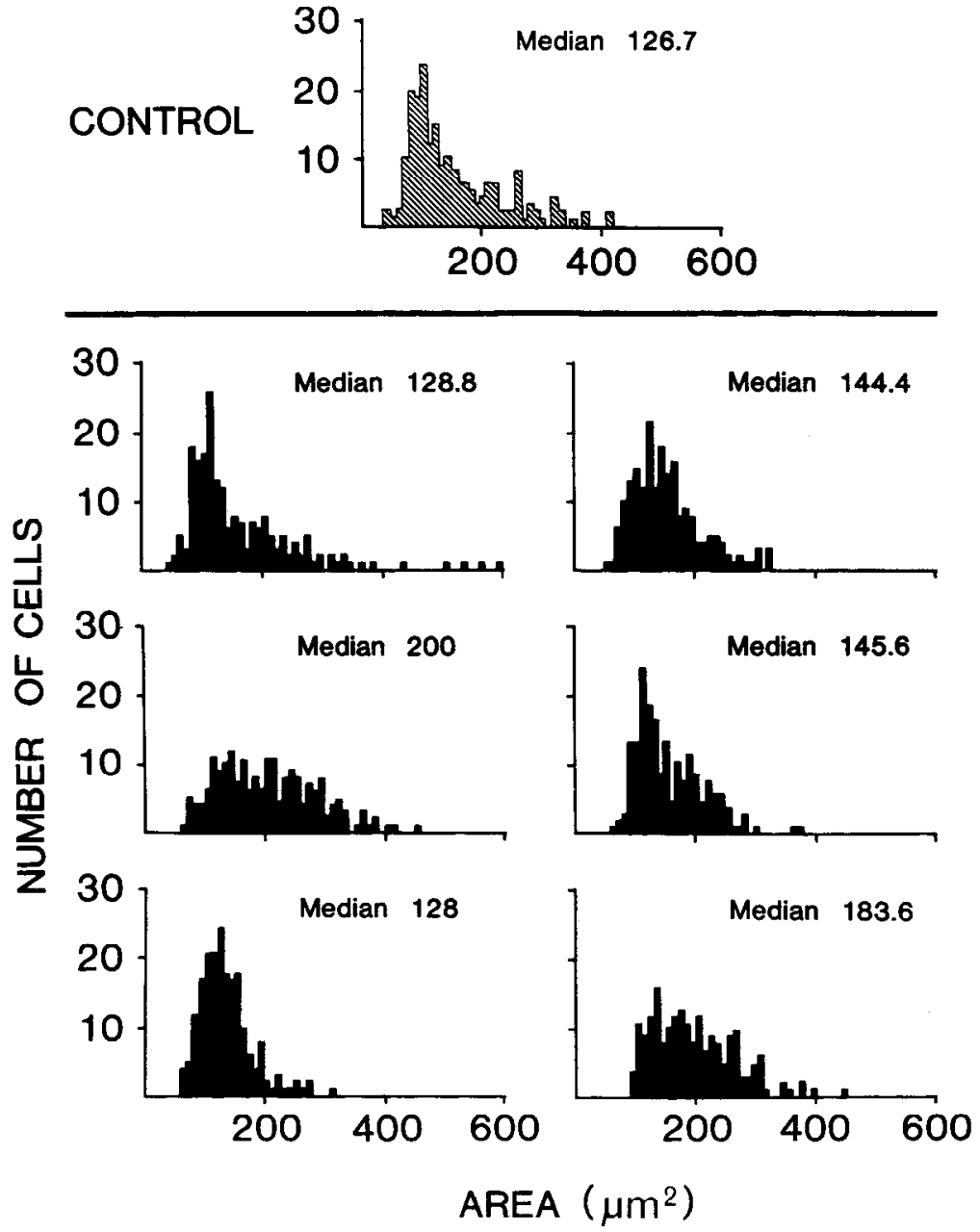

organized fiber arrangement observed at the junction between the ON stump and the graft (Fig. 7).

\section{Terminations of regenerating axons in the $S C$}

The entry of axons regenerating from the retina into the $\mathrm{SC}$ was studied in group II rats in which HRP or RITC was injected in to the eye to label the terminals of the axons regenerating from the retina. Ten of the 53 group II animals processed for anterograde labeling of axon terminals with HRP were excluded from further study because no graft or injury track was identified in the SC ( 7 animals), the graft ended in the periaqueductal gray region of the midbrain rather than the SC ( 2 animals), or perfusion-fixation was unsatisfactory ( 1 animal). In the remaining 43 HRP-injected animals (group IIa, 19; group IIb, 24), and in all 4 animals in which RITC was used as the anterograde tracer, small fascicles of the PN grafts were identified by light microscopy in the SC, usually within its superficial layers (Figs. 9, 10). As observed in other PN graft experiments (Benfey et al., 1985), narrow injury tracks caused by the grafting procedure and delineated by hemosiderin-filled macrophages typically extended up to 2 or $3 \mathrm{~mm}$ caudal to the ends of the grafts.

In the 4 animals examined after intraocular injection of RITC, fihers that were continuously labeled by the fluorescent marker could be identified by light microscopy and followed into the $\mathrm{SC}$ for distances up to $500 \mu \mathrm{m}$ (Fig. 11). Some of the RITClabeled profiles within the SC consisted of single fibers with little branching (Fig. 11,a,b); in others, the labeling pattern outlined axons that ended as arborizations (Fig. 11c). Many of these RITC-labeled profiles in the SC resembled the growth cones of regenerating RGC axons labeled along the grafts after the anterograde transport of RITC and other tracers from the eye (Trecarten et al., 1986). However, the number of axons seen to extend beyond the graft and into the midbrain was only a small fraction of the fiber population labeled at the end of the grafts (Fig. 9).

HRP reaction product was identified by light microscopy in the vicinity of the macrophage-containing injury tracks in 18 of the $\mathbf{4 3}$ group II animals with satisfactorily placed grafts (Fig. 12); no reaction product was observed in the remaining 25 animals. Large HRP-filled profiles $10-20 \mu \mathrm{m}$ in diameter were usually located within or adjacent to the injury tracks. Since most $\mathrm{ON}$ axons in adult rats range from 0.4 to $1.5 \mu \mathrm{m}$ in diameter (Richardson et al., 1982), these large labeled axons near the end of the graft in the SC may represent growth cones or terminal enlargements of regenerating axons whose rate of elongation was curtailed by the change from the PNS substrate to that of the CNS.

Smaller HRP-labeled axonal processes appeared to radiate from the larger profiles or to arise separately from the tips of the grafts. These smaller processes often ended as short arborizations (Fig. 12).

By electron microscopy, mitochondria, occasional vesicles, groups of neurofilaments, and a few microtubules could be recognized within the large labeled axons, although the HRP re- 

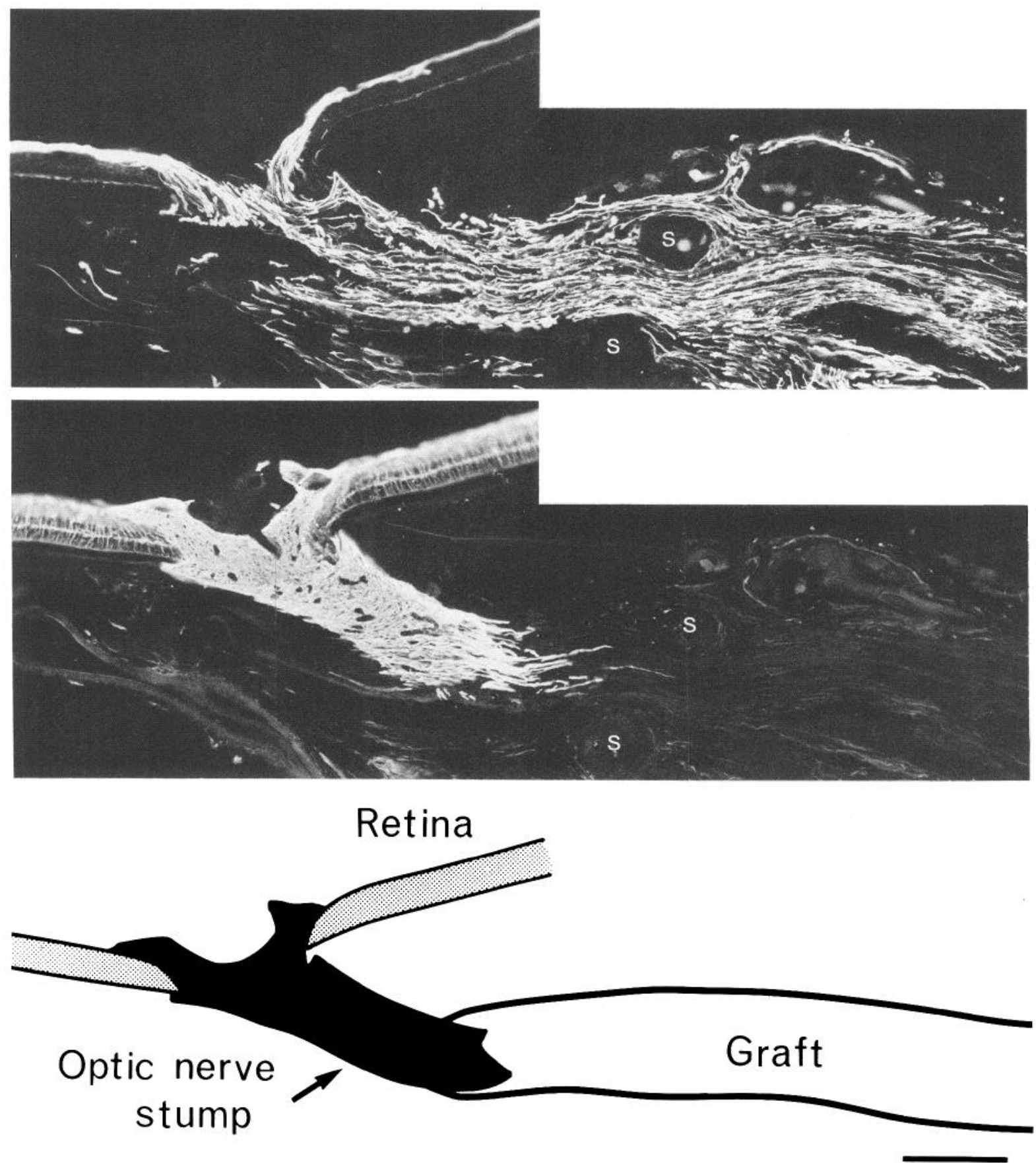

Figure 7. Radial section of the posterior part of the eye and the attached ON-PN graft from a group I animal. This section was reacted sequentially for RT 97 and GFAP immunoreactivity. S, sutures. Bar, $200 \mu \mathrm{m}$. Top, RT 97 immunofluorescence (fluorescein isothiocynate) outlines axons in the retina, the ON stump, and the attached graft. Many fluorescent axons are continuous from the ON stump to the graft. Center, Intense GFAP immunofluorescence (tetramethylrhodamine isothiocyanate) in the retina and ON stump delineates the CNS-PNS junction. Bottom, Diagram of the retina, ON stump, and graft.

action product obscured the fine detail of these structures (Figs. $13,14)$. Collections of filaments, similar to those observed in the present experiments (Fig. 13c), have also been described in the growth cones of developing optic nerves (Williams and Rakic, 1985; Williams et al., 1986) and in the terminal bulbs of transected ONs in goldfish (Lanners and Grafstein, 1980) or rats (fig. 14 of Richardson et al., 1982).

Many of the small HRP-labeled profiles often ended within the neuropil adjacent to the injury tracks (Fig. 13a) and con- tacted unlabeled neural processes, including dendrites (Fig. 13d). Although the precise ultrastructure of many of these axon profiles was obscured by heavy labeling with the TMB-DAB-Co reaction product or the effects of the peroxidase reactions, the less heavily labeled profiles were observed to contain synaptic vesicles. Some of the labeled profiles that contacted neuronal processes in the SC showed pre- and postsynaptic specializations (Fig. 15). No differences in the incidence of axonal arborizations within the SC or of synapse formation by the terminals of RGCs 
Figure 8. In this longitudinal section from a PN graft near its insertion into the $\mathrm{SC}$ in a group II animal, many axons show RT 97 immunofluorescence. Bar, $100 \mu \mathrm{m}$.

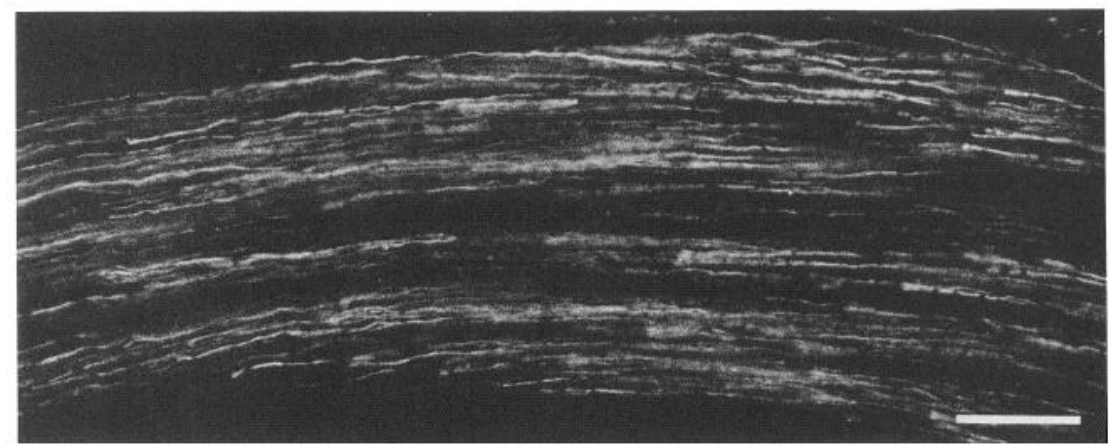

that had reentered the CNS were identified between the group IIa animals, in which the PN graft was inserted into the contralateral SC, and the group IIb animals, in which the graft was inserted into the ipsilateral SC and the nongrafted $\mathrm{ON}$ transected to increase the extent of denervation in the targeted region of the CNS.

Along their short course within the SC, the HRP-labeled profiles were not associated with $\mathrm{PN}$ components such as fibroblasts or Schwann cells and their basal lamina, although it was not

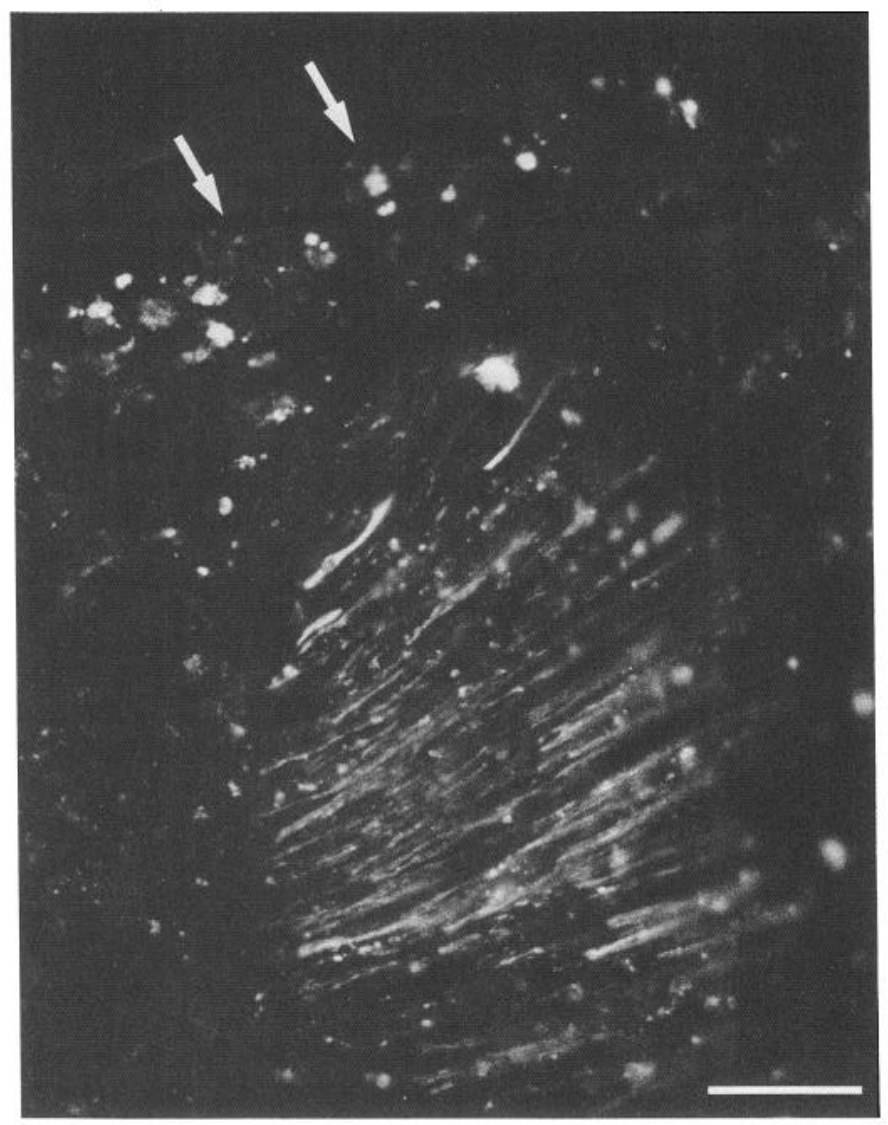

Figure 9. Preterminal portion of a PN graft anterogradely labeled with RITC $4 \mathrm{~d}$ after intraocular injection of the fluorescent tracer. The obliquely sectioned graft, approximately $100 \mu \mathrm{m}$ in diameter, is located beneath the surface of the SC (arrows) and contains many RITC-labeled axons. At the surface of the SC, there are granules of nonspecific fluorescence, which, in contrast to the specific RITC fluorescence of the anterogradely labeled axons, could also be visualized with other microscope filter combinations. Bar, $25 \mu \mathrm{m}$. possible to exclude a transient migration of some of these PN components at earlier periods after graft insertion into the SC. Near the ends of the grafts, the labeled profiles were often close to macrophages, blood vessels (Figs. $12 c ; 13, a, b$ ), or astrocytes (Fig. 14). As they extended away from the ends of the grafts and the injury tracks, both the large and small profiles contacted astrocytes, oligodendrocytes, the outer surfaces of myelinated fibers, and other components of the neuropil, including dendrites.

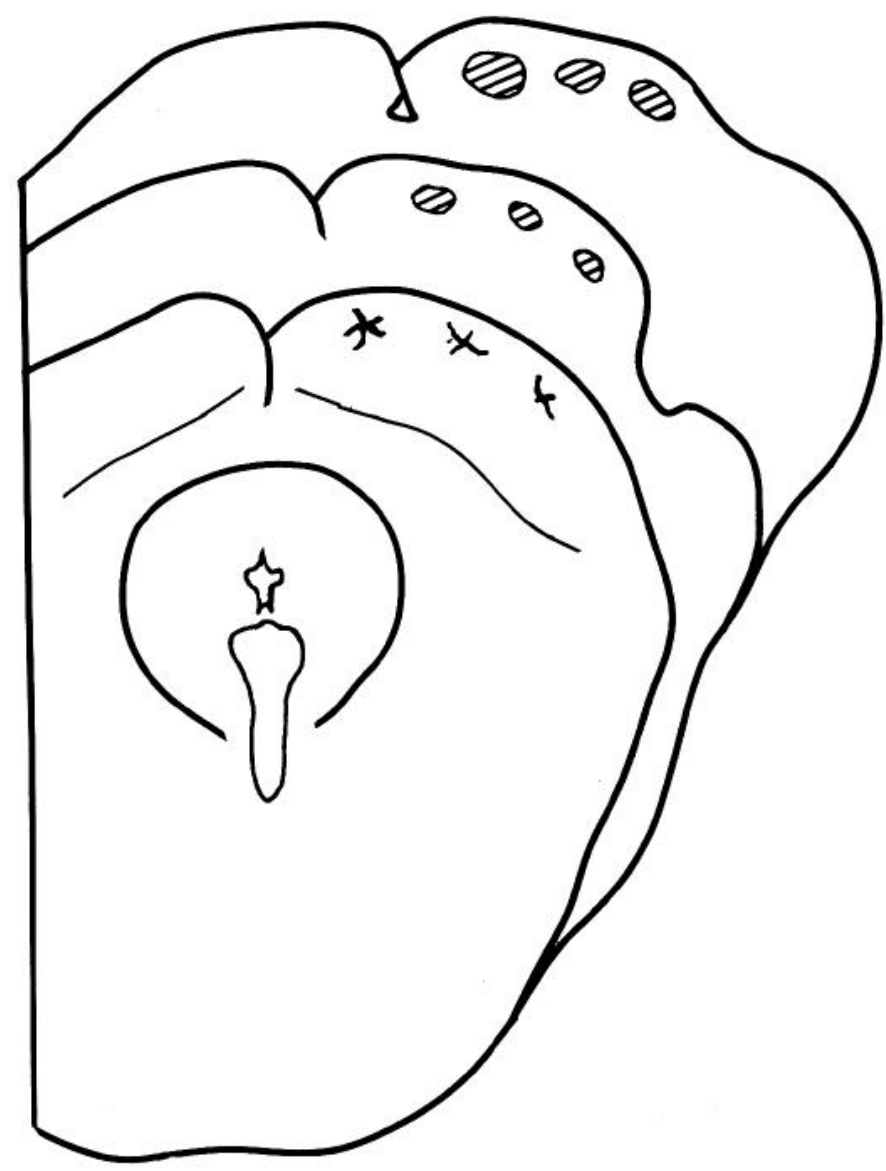

Figure 10. Schematic representation of graft locations in the midbrain. Rostrally (top), 3 small branches of a PN graft (cross-hatched) are depicted in the superficial layers of the SC. More caudally, such grafts often ended as small injury tracks associated with HRP-labeled profiles (irregular lines) that could be identified by light microscopic examination of the 50- $\mu \mathrm{m}$-thick sections embedded in epoxy resin. 

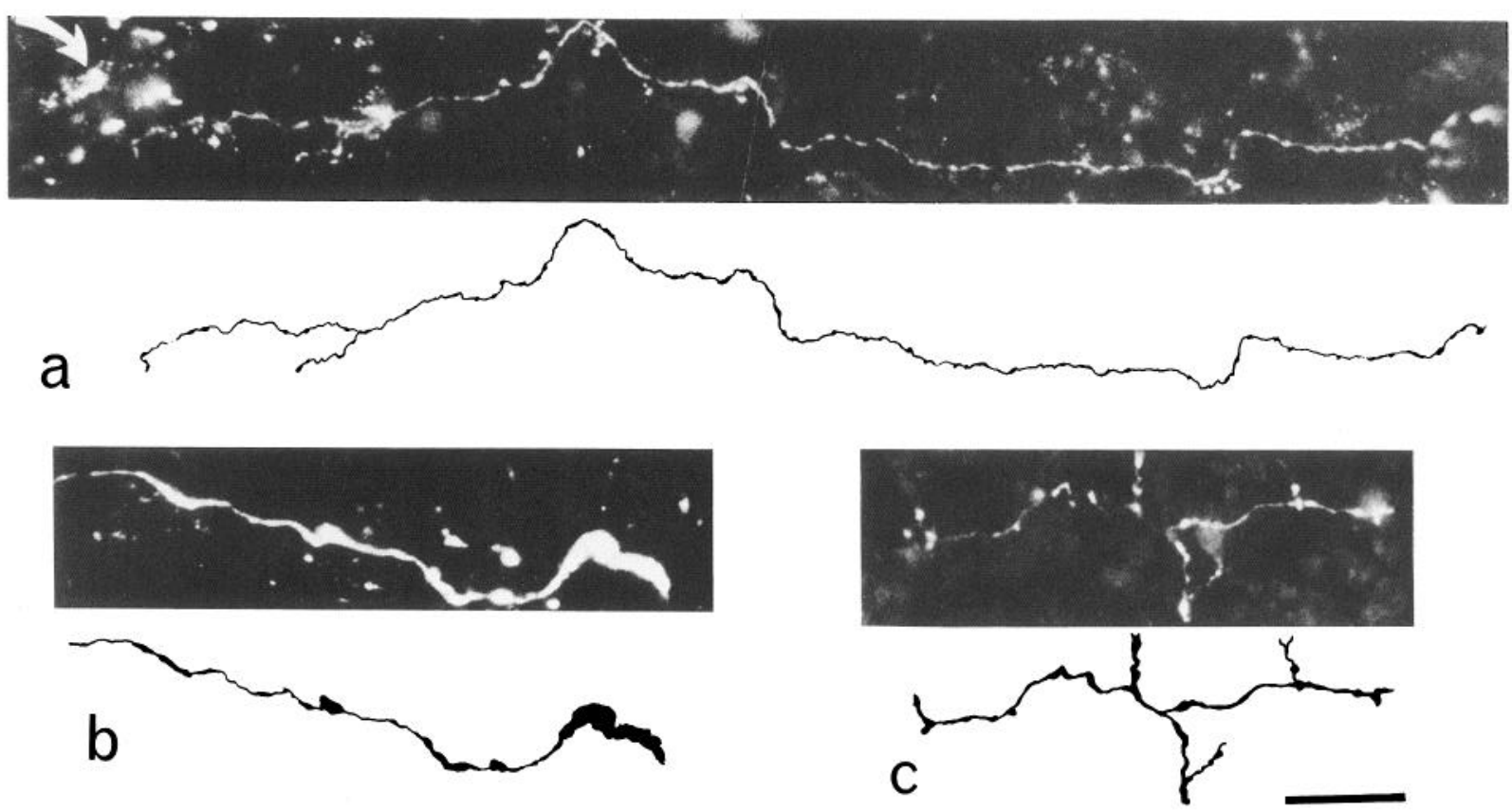

Figure 11. Fluorescence photomicrographs illustrating individual RITC-labeled axons identified within the SC near the end of the graft following intraocular injection of the fluorescent tracer. In the accompanying line drawings, axonal labeling is distinguished from the nonspecific fluorescence. Bar, $25 \mu \mathrm{m}$. $a$, An axon labeled with RITC extends from the end of the graft to the right (not shown), towards the surface (arrow) of the SC. $b$, Some RITC-labeled fibers ended as bulbous structures that resemble the growth cones seen in developing optic nerves (Thanos and Bonhoeffer, 1983). $c$, Other RITC-labeled profiles ended as small branches.

\section{Discussion}

In contrast to the extensive regrowth that follows the interruption of axons in the PNS of all vertebrates and the severing of certain CNS tracks in fish and amphibia (for review, see Grafstein, 1986), nerve fibers severed in the CNS of adult mammals fail to elongate substantially; the regenerative responses of axotomized CNS neurons in adult mammals generally appear to be restricted to short-range changes in neuronal connectivity and synapse organization (Raisman, 1985). Paradoxically, this welldocumented failure of fiber tracts to elongate and form connections in the injured adult CNS coexists with an intrinsic capability of many of the projection neurons to initiate and sustain a lengthy regrowth of their interrupted axons when the CNS environment is substituted by transplants containing nonneuronal components of the PNS (Aguayo, 1985). Furthermore, CNS neurons in experimental mammals also appear to retain a capacity to receive new inputs; certain nerve cells in the adult mammalian CNS are capable of synaptic interactions with immature neurons that are transplanted nearby (Freund et al., 1985; Sotelo and Alvarado-Mallart, 1985; Clarke et al., 1986).

Although the precise mechanisms that regulate long-range axonal extension are unknown, it can be assumed that both neuronal and non-neuronal factors play a role. The results of several in vivo and in vitro experiments support the hypothesis that both the PNS (Riopelle et al., 1981; Richardson and Ebendal, 1982; Varon et al., 1983-1984; Lander et al., 1985; FordHolevinski et al., 1986; Muller et al., 1986; Tainuchi et al., 1986) and the immature CNS (Barde et al., 1983; Matthew and Patterson, 1983; Liesi, 1985; Carbonetto et al., 1987) express components that permit or promote sustained axonal extension. Limited axonal growth in the injured CNS may result from local inhibitory influences in the CNS glial environment (Schwabb and Thoenen, 1985) or from a failure of the injured adult CNS to express appropriate growth-promoting molecules, either cellular or extracellular. To expose injured CNS axons to the effects of an environment conducive to axonal growth and to mitigate the effects of possible inhibitory influences from the CNS, we have replaced the CNS glial environment with transplanted segments of PN. Under such experimental conditions, various classes of neurons, located in several different regions of the adult mammalian CNS, have proved capable of extensive axonal growth (for review, see Aguayo, 1985).

\section{Responses of retinal ganglion cells to nerve grafts}

Previous anatomical studies of the responses of injured retinal ganglion cells in adult mammals have documented a failure of axonal elongation after crushing or cutting the optic nerve or tract (Mantz and Klein, 1951; Eayrs, 1952; Polyak, 1958; Grafstein and Ingoglia, 1982; Richardson et al., 1982; Allcutt et al., 1984; Misantone et al., 1984). However, short extensions of RGC axons within the injured retina and into PN grafts attached to the optic nerve (Tello, 1907, 1911; Leoz Ortin and Arcaute, 1914; Ramón y Cajal, 1914; Goldberg and Frank, 1980; McConnell and Berry, 1982) have been reported since early in this century in studies that used classical histologic methods. The present availability of microsurgical techniques, neuroanatomical tracers, and specific cell markers has made possible a more accurate assessment of the intrinsic capabilities of RGCs to initiate and support extensive axonal regrowth (So and Aguayo, 1985; Stevenson, 1985; Vidal-Sanz et al., 1985, 1986; Berry et al., 1986; Politis and Spencer, 1986; So et al., 1986). To investigate if such regenerating retinal axons could reach their normal targets and reform connections, we have now used transplanted 

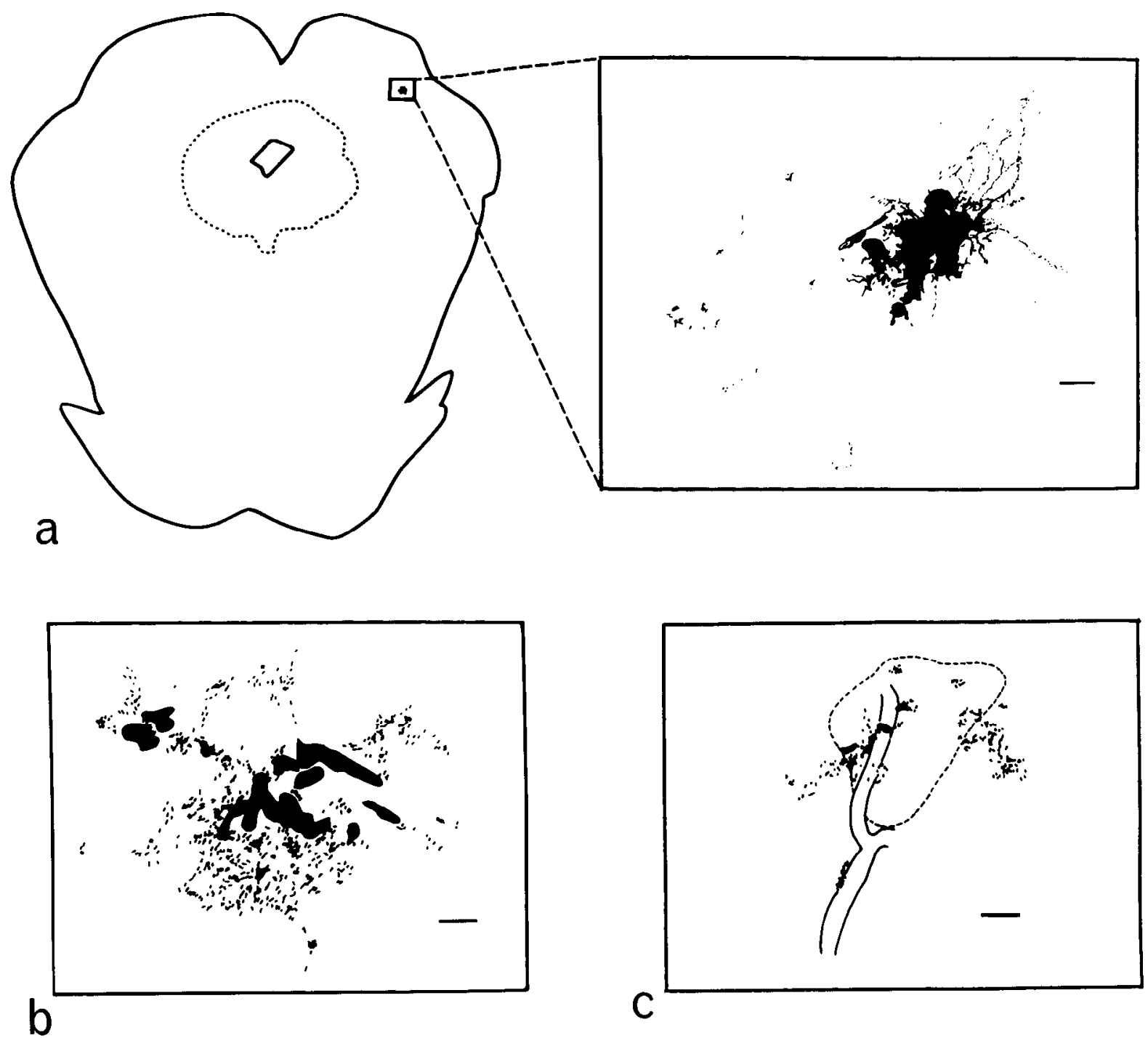

Figure 12. Drawings of HRP-labeled arborizations at the end of PN grafts connecting the retina and the SC. Bars, $20 \mu \mathrm{m}$. a, At left, diagram of epoxy resin-embedded cross section of the midbrain illustrates the location of the injury track at the end of the PN graft that had been inserted into the superficial SC in a rostral-caudal direction. Right, Camera lucida reconstruction of the complex of labeled profiles near the end of the graft. Visualized in serial sections by light microscopy, such complexes are typically composed of large, HRP-filed structures (solid black) and discontinuously labeled axonal arborizations (thin, interrupted lines). $b$. This camera lucida drawing illustrates another complex of HRP-labeled structures at the end of a PN graft in the SC. $\mathcal{C}$, This HRP-labeled profile, whose electron microscopic appearance is illustrated in Figure 13, is closely associated with a small blood vessel. The region of the injury track, which contained macrophages, is outlined by the broken line. Because the eye and the SC were only connected by the PN graft, the HRP-labeled structures are considered to be the terminals of RGC axons that have regenerated along the graft.

PN segments as "bridges" to link the eye and the SC along a course that is largely extracranial.

\section{Axotomized retinal ganglion cells as a source of axonal regrowth along nerve grafts}

In previous experiments in which PN segments were inserted directly into the superior-temporal retina, axonal regrowth originated from axotomized RGCs confined to these retinal sectors (So and Aguayo, 1985; So et al., 1986). In the present group I experiments, in which the ON was transected completely and substituted by a PN graft, the neurons that gave rise to the axons that grew along the PN grafts were distributed throughout the entire retina. In addition to the shape, size, and position of such cells, their intraretinal axonal patterns, as revealed by RT 97 immunoreactivity, and the labeling of their somas and dendrites by HRP applied to the distal end of the graft, other lines of evidence confirmed that these neurons were RGCs. In experiments in which similarly prepared animals were tested electrophysiologically, the responses to illumination of the retina suggested that RGCs had regenerated axons along these grafts 

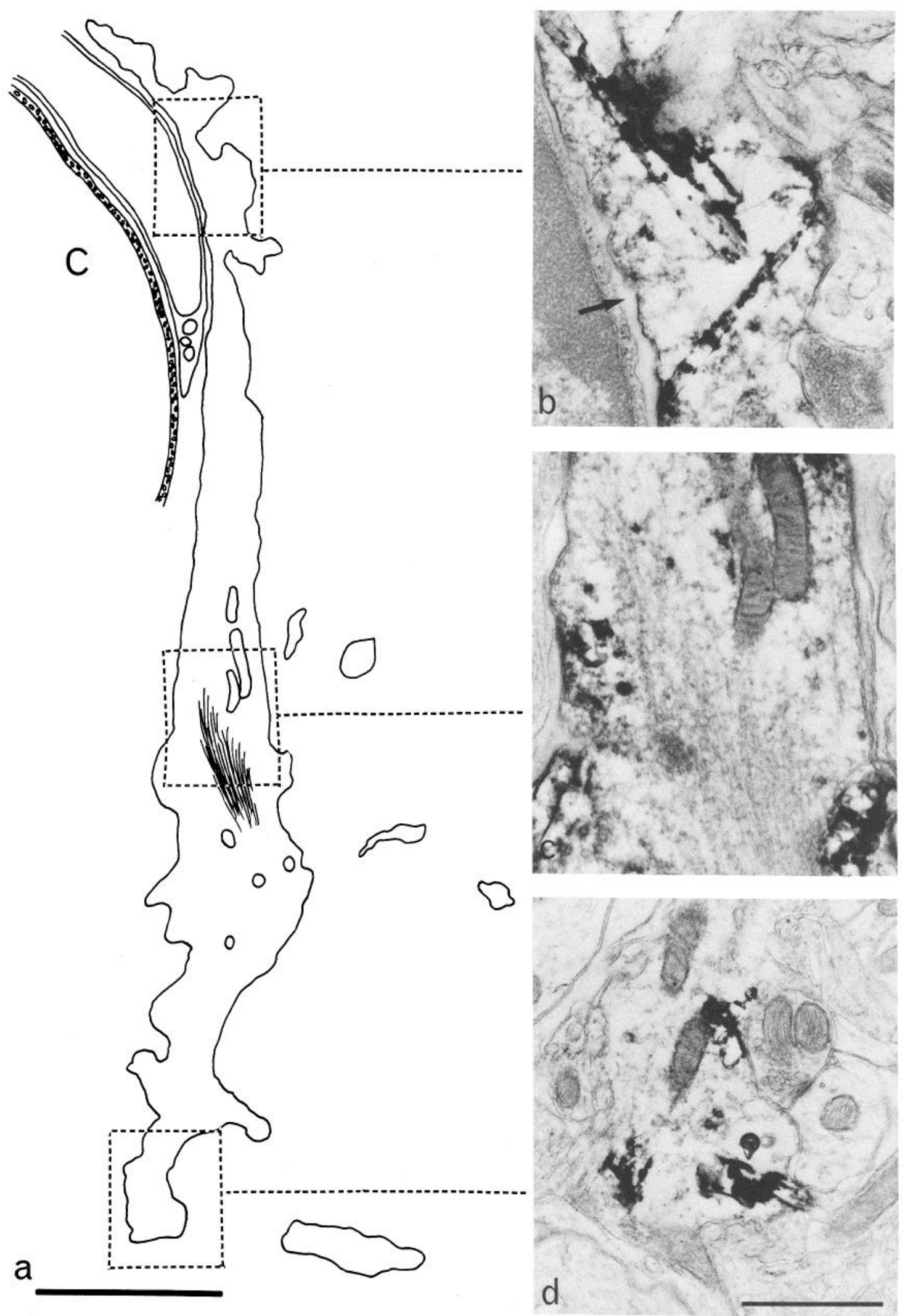

$C$, capillary. $a$, The labeled axon, shown as a line drawing prepared from an electron microscopic photomontage, passed in and out of the plane of section from the vicinity of the injury track (out of view at top of the diagram), contacted the basal lamina of a blood vessel, and ended among several small labeled profiles (outlined to right) in the neuropil of the SC. Electron micrographs of the 3 segments of this labeled axon, outlined by broken lines, are presented at right. $b$, The axolemma is closely apposed to the basal lamina (arrow) of the blood vessel. $c$, Within the axon, there is a cluster of filaments (approximately $10 \mathrm{~nm}$ in diameter), partially obscured by HRP reaction product. $d$, The labeled axon containing the linear HRP reaction product terminates in contact with a small dendrite, which is also contacted by an unlabeled presynaptic axon terminal. No synaptic contacts were identified in relation to the smaller profiles, which were presumably branches of the larger process. Bar, $20 \mu \mathrm{m}(a) ; 1 \mu \mathrm{m}(b-d)$. 


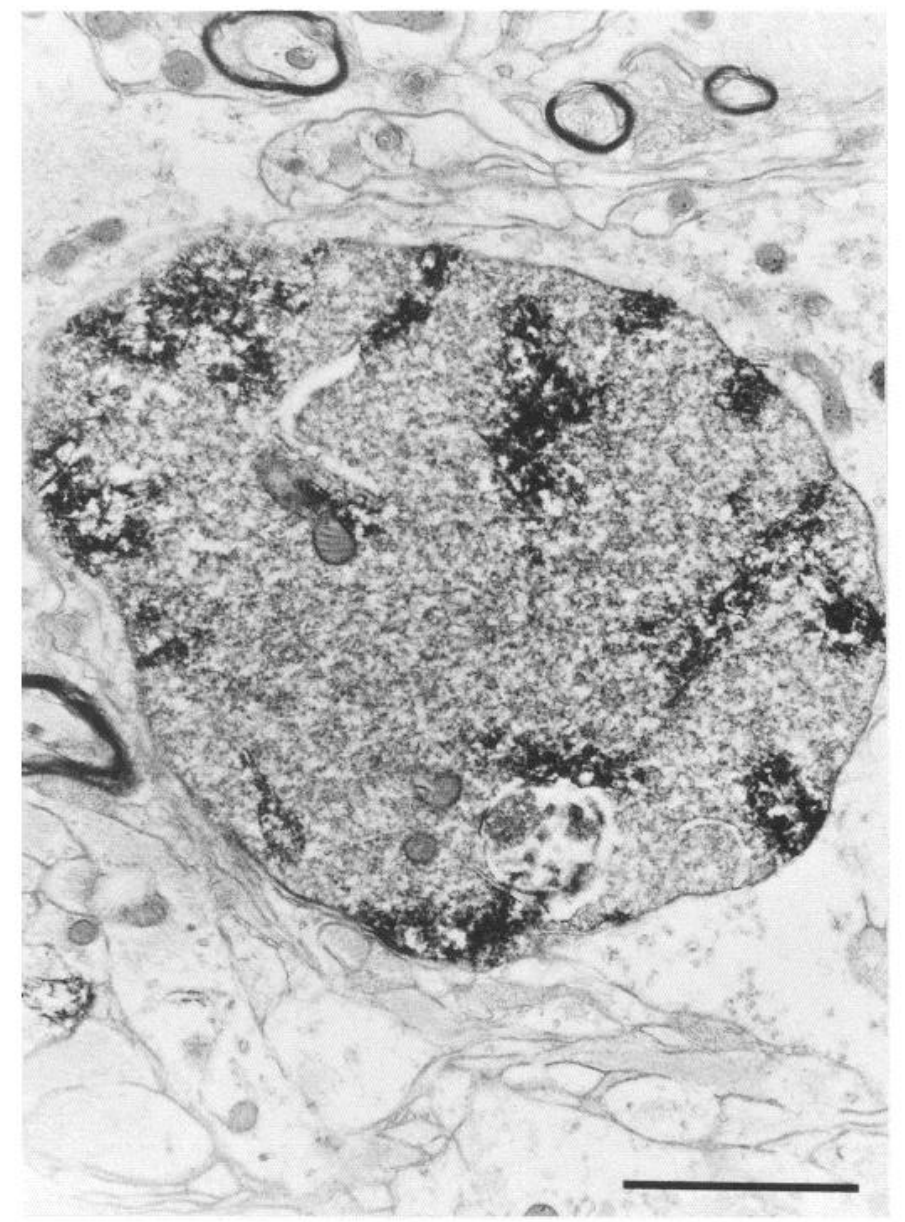

Figure 14. Large HRP-labeled axon profile, seen in cross section, contacts astrocyte processes of the injury track near the end of the graft. This densely labeled profile contains a few mitochondria and HRP reaction product manifest as the characteristic DAB-Co-stabilized TMB crystals, as well as a more diffuse peroxidase reaction product that obscures the other contents of the axon. Bar, $2 \mu \mathrm{m}$.

(Keirstead et al., 1985). Furthermore, when one retrogradely transported tracer was applied to the ON stump at the time of grafting and another was applied after regeneration, only RGCs labeled at the time of axotomy had grown into the grafts (Villegas-Pérez et al., 1987). Finally, because only axotomized cells appear to innervate these grafts (Friedman and Aguayo, 1985; So and Aguayo, 1985), it is unlikely that the severing of the optic nerve would have induced retinal neurons other than ganglion cells to produce and extend such long processes into the transplanted PN segments.

The total number of HRP-labeled neurons in these experiments indicates that up to $10 \%$ of the normal RGC population of approximately 110,000 (Forrester and Peters, 1967; Perry, 1981; Potts et al., 1982) had regenerated their axons to the site of application of the tracer, approximately $3 \mathrm{~cm}$ from the posterior pole of the eye. Because axotomy causes the death of large proportions of RGCs in these (Villegas-Pérez et al., 1986) and other experiments in which RGCs are axotomized near the cell body (Grafstein and Ingoglia, 1982; Richardson et al., 1982; Misantone et al., 1984; Berry et al., 1986), the actual incidence of regeneration among the RGCs that survived axotomy was considerably greater. Indeed, in other PN-graft experiments in which double-labeling with 2 different fluorescent tracers was used to identify surviving and regenerated ganglion cells in rats, it has been possible to confirm that as many as $20 \%$ of the surviving RGCs have regrown such lengthy axons (Villegas-Pérez et al., 1987). Furthermore, estimates of RGC populations in the presence or absence of PN grafts attached to the stump of the cut $\mathrm{ON}$ indicate that the transplants increase the number of RGCs that survive axotomy (Villegas-Pérez et al., 1987).

\section{Axonal growth along the nerve grafts}

The RGC axons that did breach the ON-graft junction became ensheathed by Schwann cells indigenous to the PN graft. Visualized by anterograde labeling with RITC, their orderly, unbranched course along the grafts extended for distances that were nearly twice the length of the normal retinocollicular projections of approximately $2 \mathrm{~cm}$ in adult normal rats (Sefton, 1968) and sufficient to reach the SC along the circuitous route provided by these grafts. This near doubling of RGC axonal length and similar observations in other neuronal populations (Benfey and Aguayo, 1982; Benfey et al., 1985) in the PN-grafted brain underscore the remarkable plasticity of injured adult CNS mammalian neurons that are provided with an environment that favors fiber growth.

\section{Extension and termination of retinal axons that reenter the $S C$}

The results of this study of RGC axonal regrowth and connectivity in rats, in which one ON was substituted by a PN "bridge" linking the eye and the SC, indicated that some RGCs survive axotomy and are capable of regenerative responses hitherto unknown in adult mammals. Some damaged RGCs not only regrew axons well beyond their natural lengths, but also appeared capable of terminal arborization and synaptogenesis. A tendency for regenerating axons to arborize within the CNS was also observed when axons regenerating from transplanted dopaminergic neurons were directed along PN grafts into the striatum of adult rats (Aguayo et al., 1984; Gage et al., 1985). Thus, it would appear that while the PN milieu is more conducive to axonal elongation, the CNS substrate tends to promote or permit axonal branching. The present indications that these CNS neurons retain their capacity to form new connections extend previous observations from other PN graft experiments in which it was demonstrated that the presumed intrinsic neuronal impediments to regenerative elongation of CNS axons are not absolute (for review, see Aguayo, 1985).

Although capable of growth and synapse formation, there was only limited penetration of the CNS by the axons that reached the SC along the 4-cm-long PN grafts; HRP-labeled axons were observed in the SC in only 18 of the 43 grafted animals, and those RGC axons that did cross the PN graft-SC junction extended within the CNS tissues for only short distances. Thus, while the PN components facilitate fiber extension along the grafts, they did not appear to enhance the penetration of regenerating axons into the CNS markedly, even in the vicinity of their natural targets. Such restricted penetration of the regenerating axons beyond the PN grafts resembles the short-range fiber extension observed when fetal retinal neurons are transplanted into the dorsal midbrain of host rats (McLoon et al., 1985), as well as the limited growth that occurs when competent axons attempt to regenerate within the CNS substance (Risling et al., 1983).

The present experiments provide further indications that local substrate conditions within the adult mammalian CNS, includ- 

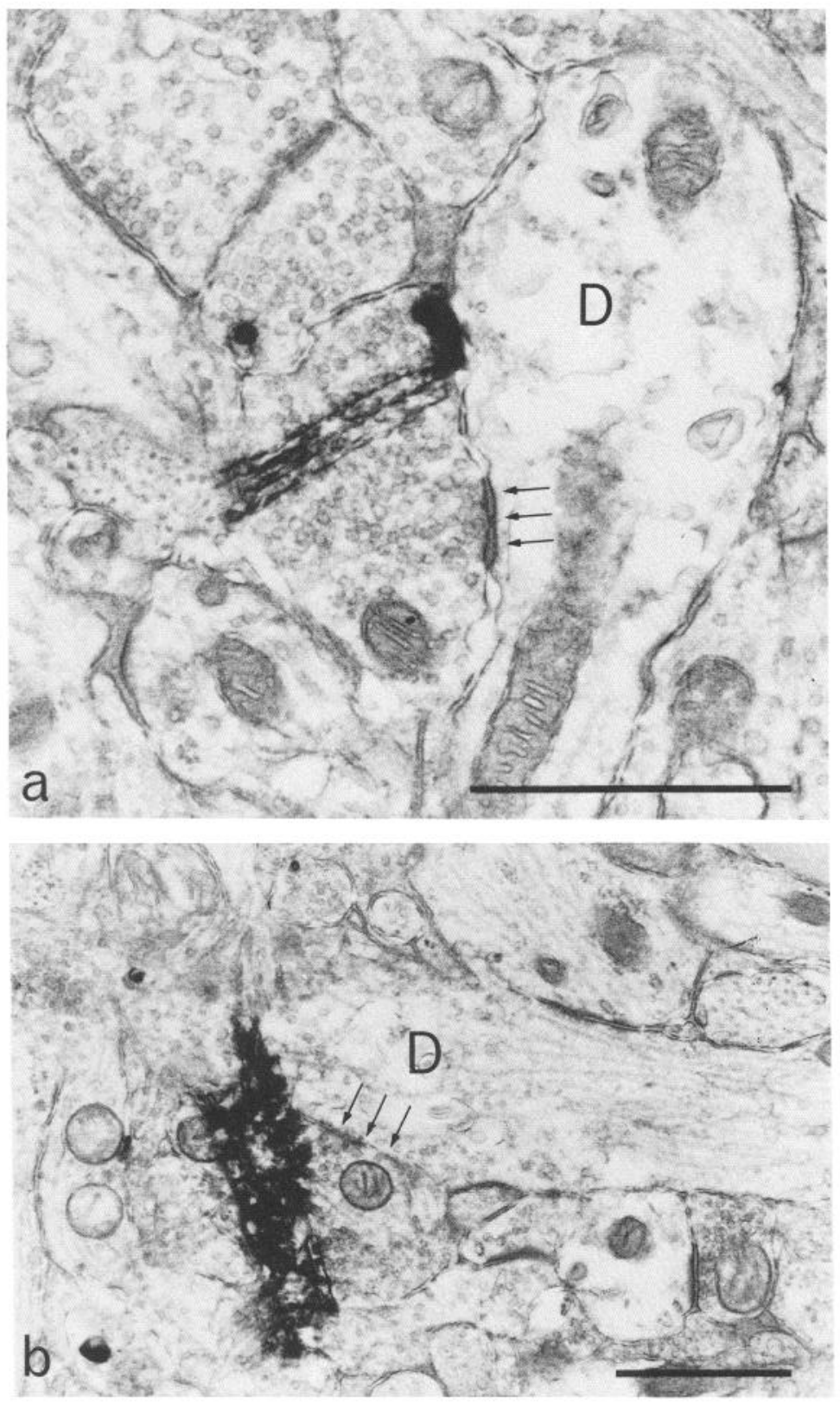

Figure 15. Electron micrographs of presynaptic profiles in the superficial SC (strata zonale and griseum superficiale) lightly labeled with HRP injected in the PN-grafted eyes of group IIb rats. $D$, dendrites. The presynaptic terminals contain vesicles that are predominantly round or spheroidal. The thickenings of the pre- and postsynaptic membranes at the synaptic contacts are indicated by arrows. $a$, Characteristic DAB-Costabilized TMB reaction product (Lemann et al., 1985) is confined to the presynaptic axon terminal. $b$, As occasionally occurs with this technique, the reaction product extends beyond the boundary of the terminal. Bars, $1 \mu \mathrm{m}$. ing possible mechanical constraints at the PN graft-SC junction, either fail to promote or actually inhibit the extension of axons that are intrinsically capable of growth and synapse formation. If the basis of this growth-limiting effect within the adult CNS could be defined more precisely and modified by experimental manipulations, it might be possible to enhance the innervation of the SC or other accessible targets in the CNS of these animals. Although our present results indicate that some of these penetrating axons do form synapses with neural elements in the SC, we do not know if the labeled synapses we observed are appropriate, sustained, or functional. Furthermore, a more extensive study of the labeled synaptic contacts will be necessary to determine if the morphological characteristics of normal retinocollicular synapses (Lund and Lund, 1972) are reconstituted following such regeneration.

In the injured visual system of immature rodents (Schneider et al., 1985), as in adult fish and amphibia (Grafstein, 1986), growing axons appear to recognize specific target neurons in the
SC. It may now be possible to explore the possibility that similar determinants of retinotopic organization are also expressed in adult mammals when regenerating retinal axons are guided back to the SC. Thus, the "bridging" of the wide gaps that separate sources and targets of innervation in adult mammals not only may permit an evaluation of regenerative neuronal capacities and the substrate conditions that stimulate or inhibit axonal extension, but may also provide new insights into the circumstances that influence interneuronal recognition and connectivity (Fujisawa, 1981; Bonhoeffer and Gierer, 1984; Taylor and Gaze, 1985), phenomena critical to the restoration of appropriate function. Although the precise mechanisms responsible for these phenomena are unknown, the findings described here suggest the possibility that the RGCs of adult mammals may be capable of replicating several different stages of both normal development and the successful regeneration of retinotectal projections that occurs in anamniotes (for review, see Grafstein, 1986). 


\section{References}

Aguayo, A. J. (1985) Axonal regeneration from injured neurons in the adult mammalian central nervous system. In Synaptic Plasticity, C. W. Cotman, ed., pp. 457-484, Guilford, New York.

Aguayo, A. I., A. Björklund, U. Stenevi, and T. Carlstedt (1984) Fetal mesencephalic neurons survive and extend long axons across PNS grafts inserted into the adult rat striatum. Neurosci. Lett. 45 : 53-58.

Allcutt, D., M. Berry, and J. Sievers (1984) A quantitative comparison of the reactions of retinal ganglion cells to optic nerve crush in neonatal and adult mice. Dev. Brain Res. 16: 219-230.

Anderton, B. H., M. J. Downes, P. J. Green, B. E. Tomlinson, J. Ulrich, J. N. Wood, and J. Kahn (1982) Monoclonal antibodies show that neurofibrillary tangles and neurofilaments share antigenic determinants. Nature 298: 84-86.

Barde, Y. A., D. Edgar, and H. Thoenen (1983) New neurotrophic factors. Annu. Rev. Physiol. 45: 601-612.

Benfey, M., and A. J. Aguayo (1982) Extensive elongation of axons from rat brain into peripheral nerve grafts. Nature 296: 150-152.

Benfey, M., U. Buenger, M. Vidal-Sanz, G. M. Bray, and A. J. Aguayo (1985) Axonal regeneration from GABAergic neurons in the adult rat thalamus: Anatomical and immunohistochemical studies. J. Neurocytol. 14: 279-296.

Berry, M., L. Rees, and T. Sievers (1986) Regeneration of axons in the mammalian visual system. Exp. Brain Res. Suppl. 13: 18-33.

Bonhoeffer, $\Gamma_{\text {., }}$ and $A$. Gierer (1984) How do retinal axons find their targets on the tectum? TINS 7: 378-381.

Buenger, U. R., and A. J. Aguayo (1983) Rat visual system neurons grow axons along PNS grafts. Soc. Neurosci. Abstr. 9: 699.

Carbonetto, S., D. Evans, and P. Cochard (1987) Nerve fiber growth in culture on tissue substrata from central and peripheral nervous systems. J. Ncurosei. 7: 610-620.

Clarke, D. J., F. H. Gage, O. G. Nilsson, and A. Björklund (1986) Grafted septal neurons form cholinergic synaptic connections in the dentate gyrus of behaviorally impaired aged rats. J. Comp. Neurol. 252: 483-492.

David, S., and A. J. Aguayo (1985) Peripheral nerve transplantation techniques to study axonal regeneration from the CNS of adult mammals. In Fernström Foundation Series, Vol. 5: Neural Grafting in the Mammalian CNS, A. Björklund and U. Stenevi, eds., pp. 61-71, Elsevier, Amsterdam.

Dräger, U. C., and A. Hofbauer (1984) Antibodies to heavy neurofilament subunit detect a subpopulation of damaged ganglion cells in the retina. Nature 309: 624-626.

Eayrs, J. T. (1952) Relationship between the ganglion cell layer of the retina and the optic nerve in the rat. Br. J. Ophthalmol. 36: 453-459.

Ford-Holevinski, T. S., J. M. Hopkins, J. P. McCoy, and B. W. Agranoff (1986) Laminin supports neurite outgrowth from explants of axotomized adult rat retinal neurons. Dev. Brain Res. 28: 121-126.

Forrester, J., and A. Peters (1967) Nerve fibres in optic nerve of rat. Nature 214: 245-247.

Freund, T. F., J. P. Bolam, A. Björklund, U. Stenevi, S. B. Dunnet, J. F. Powell, and A. D. Smith (1985) Efferent synaptic connections of grafted dopaminergic neurons rcinnervating the host ncostriatum: A tyrosine hydroxylase immunocytochemical study. J. Neurosci. 5: 603616.

Friedman, B., and A. J. Aguayo (1985) Injured neurons in the olfactory bulb of adult rat grow new axons along peripheral nerve grafts. J. Neurosci. 5: 1616-1625.

Fujisawa, H. (1981) Retinotopic analysis of fiber pathways in the regenerating retinotectal system of the adult newt Cynops pyrrhogaster. Brain Res. 206: 27-37.

Gage, F. H., U. Stenevi, T. Carlstedt, G. Foster, A. Björklund, and A. J. Aguayo (1985) Anatomical and functional consequences of grafting mesencephalic neurons into a peripheral nerve "bridge" connected to the denervated striatum. Exp. Brain Res. 60:584-589.

Gerfen, C. R., D. D. M. O'Leary, and W. M. Cowan (1982) A note on the transneural transport of wheat germ agglutinin-conjugated horseradish peroxidase in the avian and rodent visual system. Exp. Brain Res. 48: 443-448.

Goldberg, S., and B. Frank (1980) Will central nervous system in the adult mammal regenerate after bypassing a lesion? A study in the mouse and chick visual systems. Exp. Neurol. 70: 675-689.

Grafstein, B. (1986) Regeneration in ganglion cells. In The Retina, R. Adler and D. Farber, eds., pp. 275-335, Academic, Orlando, FL.
Gratstein, B., and N. A. Ingoglia (1982) Intracranial transection of the optic nerve in adult mice: Preliminary observations. Exp. Neurol. 76: 318-330.

Hanker, J. S., P. E. Yates, C. B. Metz, and A. Rustioni (1977) A new specific sensitive and noncarcinogenic reagent for the demonstration of horseradish peroxidase (HRP). J. Histochem. 9: 789-792.

Janes, R. G., and G. W. Bounds (1955) The blood vessels of the rat's eye. Am. J. Anat. 96: 357-373.

Keirstead, S. A., M. Vidal-Sanz, M. Rasminsky, A. J. Aguayo, M. Levesque, and K.-F. So (1985) Responses to light of retinal neurons regenerating axons into peripheral nerve grafts in the rat. Brain Res. 359: 402-406.

Lander, A. D., D. K. Fujii, and L. F. Reichardt (1985) Laminin is associated with the "neurite outgrowth-promoting factors" found in conditioned media. Proc. Natl. Acad. Sci. USA 82: 2183-2187.

Lanners, H. N., and B. Grafstein (1980) Early stages of axonal regeneration in the goldfish optic tract: An electron microscopic study. J. Neurocytol. 9: 733-751.

Lemann, N., C. B. Saper, D. B. Rye, and B. H. Wainer (1985) Stabilization of TMB reaction product for electron microscopic retrograde and anterograde fiber tracing. Brain Res. Bull. 14: 277-282.

Leoz Ortín, G., and L. R. Arcaute (1914) Procesos regenerativos del nervio óptico y retina con ocasión de injertos nerviosos. Trab. Lab. Invest. Biol. 11: 239-254.

Liesi, P. (1985) Laminin-immunoreactive glia distinguish regenerative adult CNS systems from non-regenerative ones. EMBO J. 4: 25052511 .

Lund, R. D., and J. S. Lund (1972) Development of synaptic patterns in superior colliculus of the rat. Brain Res. 42: 1-20.

Mantz, J., and M. Klein (1951) Recherches expérimentales sur la section et la ligature du nerf optique chez le rat. C. R. Soc. Biol. 145: 920-924.

Matthew, W. D., and P. H. Patterson (1983) The production of a monoclonal antibody that blocks the action of a neurite outgrowth promoting factor. Cold Spring Harbor Symp. Quant. Biol. 48: 625631.

McConnell, P., and M. Berry (1982) Regeneration of axons in the mouse retina after injury. Bibl. Anat. 23: 26-37.

McLoon, S. C. (1985) Evidence for shifting connections during development of the chick retinotectal projection. J. Neurosci. 5: 25702580 .

McLoon, L. K., S. C. McLoon, F.-L. F. Chang, J. G. Steedman, and R. D. Lund (1985) Visual system transplanted to the brain of rats. In Fernström Foundation Series, Vol. 5: Neural Grafting in the Mammalian CNS, A. Björklund and U. Stenevi, eds., pp. 267-285, Elsevier, Amsterdam.

Mesulam, M. M. (1978) Tetramethylbenzidine for horseradish peroxidase neurohistochemistry: A non-carcinogenic blue reaction product with superior sensitivity for visualizing neural afferents and efferents. J. Histochem. Cytochem. 26: 106-117.

Misantone, L. J., M. Gershenbaum, and M. Murray (1984) Viability of retinal ganglion cells after optic nerve crush in adult rats. J. Neurocytol. 13: 449-465.

Muller, H. W., M. J. Ignatius, D. H. Hangen, and E. M. Shooter (1986) Expression of specific sheath cell proteins during peripheral nerve growth and regeneration in mammals. J. Cell Biol. 102: 393-402.

Perry, V. H. (1981) Evidence for an amacrine cell system in the ganglion cell layer of the rat retina. Neuroscience 6: 931-944.

Perry, V. H., and R. Linden (1982) Evidence for dendritic competition in the developing retina. Nature 297: 683-685.

Politis, M. J., and P. S. Spencer (1986) Regeneration of rat optic axons into peripheral nerve grafts. Exp. Neurol. 91: 52-59.

Potts, R. A., B. Dreher, and M. R. Bennet (1982) The loss of ganglion cells in the developing retina of the rat. Dev. Brain Res. 3: 481-486.

Polyak, S. I. (1958) Origin and course of the optic nerve. In The Vertebrate Visual System, H. Kluver, ed., pp. 237-292, University of Chicago Press, Chicago.

Raisman, G. (1985) Synapse formation in the septal nuclei of adult rats. In Synaptic Plasticity, C. W. Cotman, ed., pp. 13-38, Guilford, New York.

Ramón y Cajal, S. (1914) In Estudios sobre la degeneración y regeneración del sistema nervioso $T$. II., pp. 203-218, Imprenta de Hijos de Nicolás Moya, Madrid, Spain.

Richardson, P. M., and T. Ebendal (1982) Nerve growth activities in the rat peripheral nerve. Brain Res. 246: 57-64. 
Richardson, P. M., V. M. K. Issa, and S. Shemie (1982) Regeneration and retrograde degeneration of axons in the rat optic nerve. J. Neurocytol. 11: 949-966.

Riopelle, R. J., R. J. Boegman, and D. A. Cameron (1981) Peripheral nerve contains heterogenous growth factors that support sensory neurons in vitro. Neurosci. Lett. 25: 311-316.

Risling, M., S. Cullheim, and C. Hildebrand (1983) Reinnervation of the ventral root $\mathrm{L} 7$ from ventral horn neurons following intramedullary axotomy in adult rats. Brain Res. 280: 15-23.

Rye, D. B., S. Saper, and B. H. Wainer (1984) Stabilization of the tetramethylbenzidine (TMB) reaction product: Application for retrograde and anterograde tracing, and combination with immunohistochemistry. J. Histochem. Cytochem. 32: 1145-1153.

Schneider, G. E., S. Jhaveri, M. Edward, and K.-F. So (1985) Recent Achievements in Restorative Neurology: Upper Motor Neuron Functions and Disfunctions, J. C. Eccles and M. R. Dimitrijevic, eds., pp. 292-310, Karger, Basel.

Schwab, M., and H. Thoenen (1985) Dissociated neurons regenerate into sciatic but not optic nerve explants in culture irrespective of neurotrophic factors. J. Neurosci. 5: 2415-2423.

Sefton, A. J. (1968) Innervation of the lateral geniculate nucleus and anterior colliculus in the rat. Vision Res. 8: 867-881.

Siminoff, R., H. O. Schwassmann, and L. Kruger (1966) An electrophysiological study of the visual projection to the superior colliculus of the rat. J. Comp. Neurol. 127: 435-444.

So, K.-F., and A. J. Aguayo (1985) Lengthy regrowth of cut axons from ganglion cells after peripheral nerve transplantation into the retina of adult rats. Brain Res. 328: 349-354.

So, K.-F., Y.-M. Xiao, and Y.-C. Diao (1986) Effects on the growth of damaged ganglion cell axons after peripheral nerve transplantation in adult hamsters. Brain Res. 377: 168-172.

Sotelo, C., and R. M. Alvarado-Mallart (1985) Growth and differentiation of cerebellar suspension transplanted into the adult cerebellum of mice with heredodegenerative ataxia. Proc. Natl. Acad. Sci. USA 83: 1135-1139.

Stevenson, J. A. (1985) Growth of optic tract axons in nerve grafts in hamsters. Exp. Neurol. 87: 446-457.

Tainuchi, M., H. B. Clark, and E. M. Johnson, Jr. (1986) Induction of nerve growth factor receptor in Schwann cells after axotomy. Proc. Natl. Acad. Sci. USA 83: 4094-4098.

Taylor, J. H. S., and R. M. Gaze (1985) The effects of the fiber en- vironment on the paths taken by regenerated optic nerves of Xenopus. J. Embryol. Exp. Morphol. 89: 383-401.

Tello, F. (1907) La régénération des voies optiques. Trab. Lab. Invest. Biol. 5: 237-248.

Tello, F. (1911) La influencia del neurotropismo en la regeneración de los centros nerviosos. Trab. Lab. Invest. Biol. 9: 123-159.

Thanos, S., and F. Bonhoeffer (1983) Investigations on the development and topographic order of retinotectal axons: Anterograde and retrograde staining of axons and perikarya with rhodamine in vivo. J. Comp. Neurol. 219: 420-430.

Thanos, S., M. Vidal-Sanz, and A. J. Aguayo (1987) The use of rhodamine-b-isothiocyanate (RITC) as an anterograde and retrograde tracer in the adult rat visual system. Brain Res. 406: 317-321.

Trecarten, M. J., M. P. Villegas-Pérez, M. Vidal-Sanz, S. Thanos, and A. J. Aguayo (1986) Growth of axons along peripheral nerve system grafts inserted into the retina of adult rats. Soc. Neurosci. Abstr. 12: 701 .

Varon, S., M. Manthorpe, and L. R. Williams (1983-1984) Neuronotrophic and neurite promoting factors and their clinical potential. Dev. Neurosci. 6: 73-100.

Vidal-Sanz, M., M. P. Villegas-Pérez, P. Cochard, and A. J. Aguayo (1985) Axonal regeneration from the rat retina after total replacement of the optic nerve by a PNS graft. Soc. Neurosci. Abstr. 11: 254.

Vidal-Sanz, M., G. M. Bray, and A. J. Aguayo (1986) Terminal growth of regenerating retinal axons directed along PNS grafts to enter the midbrain in adult rats. Soc. Neurosci. Abstr. 12: 700.

Villegas-Pérez, M. P., M. Vidal-Sanz, and A. J. Aguayo (1986) Effects of axotomy and PN grafting on adult rat retinal ganglion cells. Soc. Neurosci. Abstr. 12: 700 .

Villegas-Pérez, M. P., M. Vidal-Sanz, G. M. Bray, and A. J. Aguayo (1987) Influence of peripheral nerve grafts on the survival and regrowth of axotomized retinal ganglion cells in the adult rat. J. Neurosci. (in press).

Williams, R. W., and P. Rakic (1985) Dispersion of growing axons within the optic nerve of the embryonic monkey. Proc. Natl. Acad. Sci. USA 82: 3906-3910.

Williams, R. W., M. J. Bastiani, B. Lia, and L. M. Chalupa (1986) Growth cones, dying axons, and developmental fluctuations in the fiber population of the cat's optic nerve. J. Comp. Neurol. 246: 3269. 